\title{
Micromechanics of plastic deformation and phase transformation in a three-phase TRIP-assisted advanced high strength steel: Experiments and Modeling
}

\author{
Ankit Srivastava, Hassan Ghassemi-Armaki, Hyokyung Sung, \\ Peng Chen, Sharvan Kumar, Allan F. Bower
}

School of Engineering, Brown University, Providence RI 02912 USA

\begin{abstract}
The micromechanics of plastic deformation and phase transformation in a three-phase advanced high strength steel are analyzed both experimentally and by microstructure-based simulations. The steel examined is a three-phase (ferrite, martensite and retained austenite) quenched and partitioned sheet steel with a tensile strength of $~ 980 \mathrm{MPa}$. The macroscopic flow behavior and the volume fraction of martensite resulting from the austenite-martensite transformation during deformation were measured. In addition, micropillar compression specimens were extracted from the individual ferrite grains and the martensite particles, and using a flat-punch nanoindenter, stress-strain curves were obtained. Finite element simulations idealize the microstructure as a composite that contains ferrite, martensite and retained austenite. All three phases are discretely modeled using appropriate crystal plasticity based constitutive relations. Material parameters for ferrite and martensite are determined by fitting numerical predictions to the micropillar data. The constitutive relation for retained austenite takes into account contributions to the strain rate from the austenite-martensite transformation, as well as slip in both the untransformed austenite and product martensite. Parameters for the retained austenite are then determined by fitting the predicted flow stress and transformed austenite volume fraction in a 3D microstructure to experimental measurements. Simulations are used to probe the role of the retained austenite in controlling the strain hardening behavior as well as internal stress and strain distributions in the microstructure.
\end{abstract}

Keywords: TRIP-assisted multiphase steel; Mechanical testing; Microstructures; Crystal plasticity; Finite elements 


\section{Introduction}

Advanced high-strength steels (AHSS) derive their exceptional properties from a complex, heterogeneous microstructure. Single phase martensitic steels, for example, have a hierarchical microstructure consisting of laths, blocks and packet within parent austenite grains (Morito et al., 2006). Dual-phase (Kuziak et al., 2008) and quenched and partitioned (Q\&P) (Edmonds et al., 2006) steels may contain two or more phases (martensite, ferrite, retained austenite and carbides) which help achieve desired properties. There is great interest in understanding how the constituent phases in high-strength steels interact to achieve a desired strength, resistance to localized necking, and fracture resistance.

The overall behavior of AHSS is determined by microstructural features, such as the volume fraction of the constituent phases, the grain size and morphology, and by the properties of the phases themselves. Determining the properties of the phases is particularly challenging, since they cannot be characterized using conventional mechanical tests. The mechanical behavior of constituent phases of multiphase AHSS has been evaluated using recently developed advanced techniques such as in-situ neutron diffraction (Jacques et al., 2007, Cheng et al., 2008, Muránsky et al., 2008, Woo et al., 2012, Choi et al., 2013) and in-situ high energy X-ray diffraction (Cong et al., 2009, Jia et al., 2009, Sun et al., 2009). The interpretation of neutron and X-ray diffraction results is difficult if the constituent phases have similar crystal structures as is the case for ferrite and martensite. Also these diffraction measurements only provide average lattice strains as a function of macroscopic stress; hence, extracting the mechanical response of the individual phases is a formidable task.

Recently, however, a more direct approach has been developed to characterize the properties of the phases within a complex microstructure. In this approach, microscale specimens are extracted from individual phases using focused ion-beam milling, and are subsequently deformed in uniaxial compression with a flat-punch nanoindenter (Stewart et al., 2012, Ghassemi-Armaki et al., 2013a, Ghassemi-Armaki et al., 2013b, Chen et al., 2014). The stress-strain data obtained by these tests are ideally suited to calibrate crystal-plasticity based constitutive relations for the phases, which then enable the microscopic and macroscopic distributions of strain and stress in representative volume elements of the steel microstructures to be computed. To date, this approach has been used to characterize the behavior of martensite blocks and packets extracted from fully martensitic steel (Ghassemi-Armaki et al., 2013a) as well as martensite and ferrite extracted from dual-phase steels (Stewart et al., 2012, GhassemiArmaki et al., 2013b, Chen et al., 2014). 
More advanced steels, such as transformation induced plasticity (TRIP) steels and Q\&P steels, have a more complex microstructure that contains at least three phases, including metastable retained austenite (Edmonds et al., 2006, Kuziak et al., 2008). The role played by the retained austenite in these steels is of particular interest, since it undergoes deformation-induced martensitic transformation, which contributes to the plastic strain, provides a potent hardening mechanism, and improves ductility. The qualitative role of retained austenite has been explored via interrupted tensile tests, combined with in-situ neutron, high energy x-ray and electron back scattered diffraction (EBSD) experiments (Sakuma et al., 1992b, Sakuma et al., 1992a, Jeong et al., 1993, Jacques et al., 2001a, Oliver et al., 2002, Jacques et al., 2007, Cheng et al., 2008, Muránsky et al., 2008, Jia et al., 2009, Lomholt et al., 2013). These experiments have provided several insights. The volume fraction of product martensite in a specimen has been shown to increase gradually with plastic strain, tending to enhance strain hardening. The improvement in strain hardening of these steels has been found to depend primarily on the initial volume fraction and stability of the retained austenite (Sakuma et al., 1992b, Sakuma et al., 1992a). The increase in strain hardening can improve ductility by delaying localization, but it has also been suggested that increasing the initial volume fraction and/or stability of the retained austenite can enhance damage nucleation and therefore has a deleterious effect on the fracture properties of the material (Jacques et al., 2001b).

Experimental observations suggest that the martensitic transformation process in TRIP-assisted multiphase AHSS involves nucleation and growth of martensite variants within retained austenite grains (Jacques et al., 2007). This leads to a fine-phase microstructure that consists of martensite variants and untransformed austenite within a grain, in which the volume fraction of martensite progressively increases with continuing deformation (Jacques et al., 2007, Lomholt et al., 2013). The evolution of volume fraction of martensite with strain has been found to depend on the stability of the retained austenite, the orientation of the retained austenite grain with respect to the loading axis, size of the retained austenite grain, and is influenced by the strength of the other phases surrounding the retained austenite grain as well (Jeong et al., 1993, Jacques et al., 2001a, Oliver et al., 2002, Jacques et al., 2007, Lomholt et al., 2013).

Guided by these experimental studies, several constitutive models have been developed for the martensitic transformation in austenitic steel or shape memory alloys see e.g. (Olson and Cohen, 1975, Leblond et al., 1986a, Leblond et al., 1986b, Stringfellow et al., 1992, Fischer et al., 1996, Diani and Parks, 1998, Fischer et al., 2000, Govindjee and Miehe, 2001, Anand and Gurtin, 2003, Suiker and Turteltaub, 2005, Turteltaub and Suiker, 2005, Turteltaub and Suiker, 2006). Many of these are isotropic plasticity models in which the volume fraction of product martensite is an evolving state variable governed by phenomenological constitutive equations. More sophisticated models idealize the fine phase 
mixture through the use of averaging techniques and the crystallographic theory of martensitic transformation (Ball and James, 1989, Bhattacharya, 1993, Hane and Shield, 1998). In the partially transformed fine-phase mixture, there may be three contributions to the inelastic strain: the untransformed austenite may deform plastically; the transformation strain associated with the austenite-martensite transformation, and at high stress levels, the product martensite may also deform plastically. Many constitutive models assume that the martensitic transformation provides the sole contribution to the plastic strain. More generally, if all three processes take place concurrently, they are coupled. Recent formulations treat this coupling by assuming a uniform stress or strain in the fine-phase mixture (Cherkaoui et al., 1998, Thamburaja, 2005, Pan et al., 2007, Wang et al., 2008, Lee et al., 2010a, Manchiraju and Anderson, 2010) and generally neglect plasticity in either the untransformed austenite or product martensite. In some cases, an additional phenomenological coupling function is used to capture additional effects such as effect of dislocation structure (Fischer et al., 2000, Levitas et al., 2002, Iwamoto, 2004, Kouznetsova and Geers, 2008).

Previous attempts to model the role of retained austenite in multiphase TRIP-assisted AHSS have been limited. In one set of studies, the effective macroscopic mechanical behavior and the influence of retained austenite have been explored through the use of homogenization techniques together with a phenomenological description of the martensitic transformation (Perlade et al., 2003, Lani et al., 2007, Delannay et al., 2008, Han et al., 2009). In another approach, calculations were carried out using volume elements consisting of a retained austenite grain embedded in a matrix material. The phases were modeled using constitutive relations developed for austenitic steels or shape memory alloys (Suiker and Turteltaub, 2005, Tjahjanto et al., 2006, Sierra and Nemes, 2008). Efforts have also been made towards microstructure based modeling using 2-D idealization of the microstructure and assuming simple elasticplastic constitutive relations with isotropic hardening for each phase together with a phenomenological description of phase transformation (Choi et al., 2009, Soulami et al., 2010).

All existing microstructure-based models of AHSS rely on phenomenological constitutive equations to describe the behavior of the phases present in the material. Determining accurate values for the properties of the phases has been a significant challenge. A common approach has been to select parameters to fit the macroscopic flow response (Perlade et al., 2003, Han et al., 2009) or to fit the parameters to match the lattice strain measured using neutron or X-ray diffraction techniques (Lani et al., 2007, Delannay et al., 2008, Choi et al., 2009, Soulami et al., 2010). These experiments probe the collective behavior of the overall microstructure and therefore, extracting material properties from the data is not straightforward. In addition, fitting simulation predictions to experimental data is often poorly conditioned, in the sense that a 
wide range of parameter values will fit the data. In contrast, the ability to extract micron-scale specimens from a microstructure provides a more direct approach, and has been applied successfully to determine properties for the constituent phases present in both fully martensitic steel (Ghassemi-Armaki et al., 2013a) and dual-phase steels (Chen et al., 2014).

In this paper, our goal is to determine the properties of the constituent phases, in particular that of retained austenite, in a third generation three-phase TRIP-assisted AHSS, and to establish their influence on the macroscopic deformation response, using a combination of experiments and numerical simulations. The material under consideration is a Q\&P980 sheet steel from Baosteel. The as-received microstructure is composed primarily of martensite and ferrite phases with dispersed fine retained austenite grains at the interfacial boundaries. In the as-received condition, the microstructure of the material consists of $44 \pm 2 \%$ by volume of the martensite phase and $\sim 8-10 \%$ by volume of the retained austenite phase; the rest is ferrite. The Q\&P980 steel possess both high strength (minimum tensile strength of 980MPa) and good ductility. In general the high strength of this steel is attributed to martensite and the good ductility is attributed to TRIP-assisted behavior of retained austenite during deformation (Wang and Speer, 2013).

The macroscopic tensile stress-strain response of the material is measured and the martensitic phase transformation of retained austenite phase is tracked using a combination of macroscale interrupted tensile tests and EBSD analysis. The mechanical behavior of the ferrite and martensite phases present in the steel are then characterized using micropillar compression tests. These provide stress-strain curves for single crystal specimens of ferrite with several crystallographic orientations and for martensite specimens consisting of single or multiple blocks. The retained austenite grains in the steel are too small to be characterized directly using micropillar compression tests. However, the properties of the retained austenite, and its effects on deformation and macroscopic behavior of the steel are determined with the aid of numerical simulations.

To this end, we have developed a microstructure-based model to study the mechanisms of deformation in the steel. The model idealizes the martensite, ferrite and retained austenite phases using crystal plasticity constitutive relations. The hierarchical structure of martensite is modeled by treating each block as a single crystal in which the laths are represented by an evolving dislocation density (as in Hatem and Zikry (2009), Wu et al. (2013)). The ferrite is modeled using a constitutive relation formulated by Weinberger et al. (2012) that accounts for departures from Schmid's law commonly observed in body centered cubic (BCC) crystals. The retained austenite is idealized using a constitutive relation that accounts for martensitic transformation as well as elastic and plastic deformation in both the untransformed austenite 
and product martensite. The martensitic transformation is based on the crystallographic theory of martensite following an approach proposed by Anand and Gurtin (2003) and the plasticity in untransformed austenite as well as in the product martensite is described by crystal plasticity based constitutive relations.

The experimental data from micropillar tests are used to determine material parameters for the ferrite and martensite phases in the steel, following the approach previously used to study martensitic and dual-phase steels in Ghassemi-Armaki et al. (2013a), Chen et al. (2014). The properties of the retained austenite are then determined by fitting the predicted macroscopic flow behavior and transformed austenite volume fraction in three-dimensional representative volume elements subjected to uniaxial tensile straining to experimental measurements. Having fully calibrated the model, we create a series of 'virtual' microstructures and study their response to uniaxial tensile straining to probe the role of retained austenite in controlling the macroscopic response of the steel, as well as to understand the microscopic strain and stress distributions in the microstructure.

The remainder of the manuscript is organized as follows. In Section 2, we describe our experimental procedure and results; Section 3 describes the microstructure-based model and the procedure used to extract material parameters from experimental data. Section 4 compares model predictions with experiment in detail, and discusses their implications. The conclusions of this work are summarized in Section 5.

\section{Experiments}

\subsection{Experimental Procedure}

The material examined in this study is a quenched and partitioned (Q\&P) three-phase (ferrite, martensite and retained austenite) sheet steel from Baosteel (Wang and Speer, 2013) with a tensile strength of $\sim 980$ $\mathrm{MPa}$. The sheet thickness is $1.1 \mathrm{~mm}$ and the nominal chemical composition of the steel is $0.2 \% \mathrm{C}-1.5 \%$ $\mathrm{Si}-1.8 \% \mathrm{Mn}-0.02 \% \mathrm{P}-0.05 \% \mathrm{Al}$ (all in wt. \%). The material was received in a fully commercially heattreated condition.

To determine the macroscopic flow behavior, uniaxial tensile specimens with a $25.4 \mathrm{~mm}$ gauge length and flat dog-bone geometry were cut from the sheet and were deformed in uniaxial tension at a nominal strain rate of $10^{-3} \mathrm{~s}^{-1}$. Specimens were cut with tensile axis parallel and normal to the rolling direction to 
determine whether any in-plane anisotropy was present. In addition, interrupted tensile tests were also performed to obtain specimens with different levels of plastic strains (5\% and 12\%) for further characterization of the deformed microstructure and its evolution with strain.

Both in-plane and out-of-plane sections were taken from as-received steel sheet and deformed tensile test specimens to characterize the microstructure. The metallographic specimens were mechanically ground and polished and finally electropolished (at $20 \mathrm{~V}$ and at a temperature of $-40^{\circ} \mathrm{C}$ ) in an aqueous electrolyte consisting of perchloric acid and ethanol in a 1:9 ratio for microstructural observations. EBSD orientation maps were acquired from these samples, using a FEI, Helios Nanolab 600 FEG-SEM, fitted with an automated HKL-EBSD pattern collection system with a spatial resolution of $\sim 80 \mathrm{~nm}$.

Micropillar compression specimens were extracted from the ferrite and martensite phases in the asreceived microstructure. The diameters of the micropillars were between $1 \mu \mathrm{m}$ and $2 \mu \mathrm{m}$ with an aspect ratio $\geq 2$. These cylinders were milled in the dual beam Focused Ion Beam (FEI, Helios Nanolab 600 dual beam FIB) using $30 \mathrm{keV} \mathrm{Ga} \mathrm{ions} \mathrm{(for} \mathrm{further} \mathrm{details} \mathrm{see} \mathrm{Ghassemi-Armaki} \mathrm{et} \mathrm{al.} \mathrm{(2013b)),} \mathrm{the} \mathrm{diameters}$ at the top surface and at a location one third of the way up from the bottom of each micropillar were measured and averaged for calculation of nominal stress. In instances where the top surface of the micropillar was rough, for example, as a result of prior light etching to distinguish the two phases, a thin layer was milled off from the top surface by FIB-assisted etching. The micropillar surface normal was determined by EBSD; the orientation within a single ferrite micropillar varied by no more than $2^{\circ}$ whereas in martensite the orientation varied with location on the top surface of the pillar, the extent differing from pillar to pillar. This observation is consistent with the hierarchically-scaled microstructure of lath martensite (laths, blocks and packets).

Uniaxial compression experiments were performed on the micropillars using the Hysitron Triboscope nanoindenter with a $10 \mu \mathrm{m}$ diameter flat-punch diamond tip. All the micropillar compression tests were conducted at a nominal constant strain rate of $10^{-3} \mathrm{~s}^{-1}$. This set of experiments makes it possible to determine the stress for onset of plastic flow and the early stage hardening of the ferrite and martensite phases.

\subsection{Experimental Results}

Representative SEM images of the multiphase microstructure of Q\&P980 sheet steel in the as-received condition are shown in Figs. 1(a) and (b). The images were taken from an electropolished and lightly- 
etched specimen. The ferrite phase appears featureless, whereas martensite has a striated appearance. Martensite appears to form a "necklace" microstructure around ferrite islands, but it is worth noting that both martensite/ferrite and ferrite/ferrite interfaces are present. Retained austenite particles, roughly equiaxed in shape and sub-micron in dimensions, are observed at triple junctions and interfaces, and are highlighted by black arrows in the higher magnification image in Fig. 1(b) and labeled as RA. Energy Dispersive X-ray (EDX) analysis of some of the larger austenite particles confirmed the presence of C, Si and $\mathrm{Mn}$ in solid solution.

Multiple EBSD images from both in-plane and out-of-plane sections were taken to assess the presence of texture in the as-received sheet steel. A representative EBSD map and the associated inverse pole figures for the phases indexed are presented in Fig. 1(c). Martensite and ferrite (both indexed as BCC) were differentiated by comparing the EBSD image with the reference secondary electron image. Retained austenite (indexed as FCC) is readily distinguished by EBSD, and can be seen as the black colored features in Fig. 1(c). The orientation scatter of the phases in the standard inverse pole figures shows that the as-received sheet steel does not possess a pronounced texture. In the as-received condition, the steel contains $44 \pm 2 \%$ martensite phase and $\sim 8-10 \%$ retained austenite phase, with the rest being ferrite. The rough estimate of the volume fraction of martensite phase was made using multiple SEM images while that of retained austenite was made using the EBSD map.

Uniaxial tensile stress-strain curves are presented in Fig. 2. Initial yielding at $\sim 400 \mathrm{MPa}$, is followed by steep work-hardening until about $800 \mathrm{MPa}$, beyond which the work-hardening rate begins to decrease appreciably. The specimens have an ultimate tensile strength (UTS) just under $1000 \mathrm{MPa}$ at an engineering strain of $\sim 22 \%$ in the rolling direction and $\sim 17 \%$ in the transverse direction. The specimens fail shortly beyond the UTS with a final fracture strain of $\sim 25 \%$ in the RD and $\sim 20 \%$ in the transverse orientation. Similar initial yielding followed by steep work-hardening was also observed for the two dualphase steels with strength levels comparable to Q\&P980 by Chen et al. (2014). However, beyond the steep work-hardening regime, the work-hardening rate of the dual-phase steels decreased more rapidly than that for the Q\&P980 steel. The final fracture strain for the two dual-phase steel evaluated byChen et al. (2014) was around $14-15 \%$.

In order to track the transformation of retained austenite to martensite during deformation, interrupted tensile tests were conducted to $5 \%$ and $12 \%$ plastic strains. The results of these experiments are shown in Figs. 3(a)-(d). From these distribution plots, it is noted that (i) the coarser particles transform to martensite more readily than do the finer particles, and (ii) there is an increase in the fine sizes with 
increasing specimen tensile strains (as determined by EBSD), suggesting that only a part of the individual particles may be transforming to martensite, thereby casting the residual untransformed fraction of the particle into a finer size bin.

Micro-pillar compression experiments were conducted on both ferrite and martensite extracted from the steel. Results for five ferrite micropillars, with pillar diameters in the range of 1.0-1.6 $\mu \mathrm{m}$ and an aspect ratio of $\sim 2-3$, and with various loading axis orientations, are shown in Fig. 4, along with representative post-deformation SEM images. The onset of yielding in these micropillars is orientation dependent, with average yield strength of about 400MPa. The general range of orientation dependent yielding of ferrite micropillars in Fig. 4 is in reasonable agreement with the yielding response of ferrite micropillars of comparable size in another dual-phase steel with similar C and Mn levels but lower Si content (GhassemiArmaki et al., 2013b, Chen et al., 2014). It is also noted that the initial stage work-hardening of ferrite pillars is not very high and the maximum stress observed in the first 5\% strain is around 500-600MPa. Post-deformation observation of the micropillars in the SEM confirmed multiple slip in some (pillars 1, 4 and 5) while single slip prevailed in others (pillars 2). This latter observation is in line with pillar 2 exhibiting a low hardening response. Pillar 3 initially exhibits a low hardening response similar to pillar 2, but exhibits a higher hardening response later and therefore, post-deformation observation does not provide conclusive information on the early response.

Analogous compression stress-strain curves for four martensite micropillars are presented in Fig. 5. Once again, the pillar diameters were in the 1.2-1.6 $\mu \mathrm{m}$ range. Three of the four curves (micropillars 1, 2 and 4) showed identical response with positive work-hardening. In contrast, micropillar 3 showed zero workhardening and an examination of this deformed pillar confirms what appears to be single slip (see images in Fig. 5). The onset of yielding appears to be in the 800-1000 MPa regime. The response of these martensite micropillars is similar to the behavior of martensite micropillars extracted from a dual-phase (ferrite-martensite) steel DP980 reported in Chen et al. (2014). In dual-phase steels, TEM sections were taken from pillars that exhibited both hardening and non-hardening behavior. It was shown that the nonhardening pillars contained a single martensite block, which allowed them to deform in single slip. Martensite pillars that exhibited a hardening response contained multiple blocks, and the hardening response was shown to be a consequence of constraints that developed at block boundaries. It is also worth noting that the DP980 has a nominal carbon content of $0.09 \mathrm{wt} \%$ and contains $\sim 60 \%$ martensite, whereas the nominal carbon content of Q\&P980 is $0.2 \mathrm{wt} \%$ and it contains $44 \pm 2 \%$ martensite. If the martensite strength is correlated directly with the carbon content, this suggests that significant amount of 
carbon goes to the retained austenite phase present in Q\&P980 steel following the quenching and partitioning heat treatment (Edmonds et al., 2006).

The retained austenite particles are too small to be characterized directly using micropillar compression tests. Since the properties of martensite and ferrite are known however, the properties of retained austenite can be inferred indirectly from the macroscopic stress-strain behavior. This requires the overall response of the microstructure to be computed, as outlined in the next section.

\section{Microstructure Based Modeling}

We next describe our microstructure-based model of Q\&P980 steel. We consider three separate phases: ferrite, martensite, and retained austenite as shown schematically in Fig. 6. Our goal is to compute the distributions of stress and plastic strain in the microstructure when it is subjected to some prescribed macroscopic stress or strain path, and hence to determine its overall macroscopic stress-strain behavior, as well as to identify potential failure sites within the microstructure.

To this end, the ferrite and martensite phases are described using crystal plasticity based constitutive relations as in Chen et al. (2014). In addition, we describe a new model that is intended to capture the behavior of retained austenite in TRIP-assisted AHSS. It accounts for plasticity in the austenite prior to transformation; the strain resulting from the austenite-martensite transformation, as well as plastic flow in the product martensite. In all simulations and experiments, we focus on room temperature isothermal deformation. Although it is possible to account for thermal effects by incorporating additional phenomenological temperature-dependent terms to the crystal plasticity based constitutive relations, our micropillar compression tests were only conducted at room temperature, and therefore, it would not be possible to calibrate the temperature-dependent constitutive parameters. The constitutive material models for all three phases are implemented as user-material subroutine in the commercial finite element code ABAQUS Standard v6.10 (Dassault Systemes Simulia Corp., 2010).

In the following sections, we first describe the process used to generate an idealized three-dimensional finite element model of the microstructure shown in Fig. 6. We then summarize the standard field equations that are used to describe deformation in the representative volume element. A brief review of the models used to characterize plastic flow in the ferrite and martensite phases is given in Sections 3.3 and 3.4. The constitutive model for retained austenite to capture the deformation mechanism 
schematically shown in Fig. 6 is described in Section 3.5. The calibration of constitutive model parameters is detailed in Section 3.6.

\subsection{Generation of 3-D three-phase RVE}

The experimental observations described in Section 2 demonstrated that (i) the Q\&P980 steel under consideration possesses no pronounced texture; (ii) the matrix is comprised of ferrite grains; (iii) martensite particles form a "necklace" microstructure around ferrite islands; and (iv) retained austenite grains are largely present at the interphase boundaries. Based on this information, a 3D idealization of the microstructure is generated as follows.

First, a 3-D polycrystalline ferrite grain structure is generated using a simulated annealing process (Saylor et al., 2004) with brick meshing (see Fig. 7). A random crystallographic orientation $[A]_{\alpha}$ is assigned to each ferrite grain, which generates a random initial texture. Simulations account for the evolution of texture during deformation, but in tension tests, necking and fracture generally occur before a significant deformation texture is established. Second, the formation of martensite and retained austenite is simulated by nucleating grains that are intended to represent prior austenite coexisting with the ferrite grains. These grains are assigned a random orientation $[A]_{\gamma}$, and are grown at a fast rate along ferrite grain boundaries and at a slow rate along other directions, with a ratio of $2: 1$. The growth of prior austenite particles is terminated when its volume fraction reaches a prescribed target value (the combined volume fraction of martensite and retained austenite in the material). After this second step, the ferrite corresponds to the volume fraction of ferrite phase in the final microstructure. This step represents the formation of the observed "necklace" microstructure of martensite and retained austenite around the ferrite grains. A similar procedure was used by Chen et al. (2014) to generate microstructures for dual-phase steels.

Next, the prior austenite grains are partitioned randomly to produce the retained austenite grains and the martensite regions observed in the final structure, with the retained austenite grains being located on the interfaces between the ferrite and the "to-be-martensite" regions. These retained austenite grains inherit the crystallographic orientation $[A]_{\gamma}$ of their parent prior austenite grains, and are grown into the prior austenite grains until a target volume fraction (corresponding to the volume fraction of retained austenite phase in the material) is reached. When this step is completed, the microstructure contains the (BCC)

ferrite grains with orientations $[A]_{\alpha}$; the (FCC) retained austenite grains with orientation $[A]_{\gamma}$ together 
with a residual volume of prior austenite, with the same orientation, which will be converted to martensite (in the next step).

The final step is to generate the hierarchical microstructure of martensite in the remaining prior austenite grains. The generation of martensite microstructure is detailed in Ghassemi-Armaki et al. (2013a). The prior austenite particles are divided into packets using $L_{\infty}$ Voronoi tessellation. An element is selected at random within each prior austenite particle to act as the Voronoi center. The distance between Voronoi centers and other elements in prior austenite particle is measured by the $L_{\infty}$ norm or maximum norm. The number of Voronoi centers in each prior austenite grain controls the packet size. One of four $\{111\}_{\gamma}$ habit planes in the Kurdjimov-Sachs (K-S) family of orientations is randomly chosen for each packet. Finally, each packet is sub-divided into blocks, using a similar $L_{\infty}$ Voronoi tessellation. The number of Voronoi centers in each packet controls the block size. One orientation variant selected at random from the six possible K-S orientation variants of each packet group is assigned to each block. The orientations of the blocks $[A]_{\alpha^{\prime}}$ are related to the orientations $[A]_{\gamma}$ of prior austenite grain via the transformation $[T]=[A]_{\alpha^{\prime}}[A]_{\gamma}^{-1}$ which can be derived from the $24 \mathrm{~K}-\mathrm{S}$ orientation variants.

Figure 7 illustrates a representative volume element (RVE) that was generated using this procedure. The size of RVE is $100 \times 100 \times 100 \mu m$, and is meshed using 125000 C3D8 brick elements of the ABAQUS Standard v6.10 (Dassault Systemes Simulia Corp., 2010) element library. In the mesh shown, the ferrite phase consists of 57483 elements, the martensite phase is meshed using 54951 elements, while the retained austenite particles consist of 12566 elements. This gives $\sim 46 \%$ ferrite, $\sim 44 \%$ martensite and $\sim 10 \%$ retained austenite.

In simulations, periodic boundary conditions are imposed on all six faces of the representative volume element shown in Fig. 7. A uniaxial tensile deformation is simulated by subjecting the cell to a prescribed constant nominal strain rate parallel to the $\mathbf{e}_{1}$ axis, while maintaining zero resultant forces on planes perpendicular to the $\mathbf{e}_{2}, \mathbf{e}_{3}$ directions.

\subsection{Field Equations}


The goal of our numerical simulations is to compute the internal stress and strain distributions within the representative volume element described in the preceding section, as it is subjected to a prescribed macroscopic strain. We describe the deformation within the cell in the usual way: a point at position $\mathbf{X}$ in the initial microstructure moves to a new position $\mathbf{x}=\mathbf{X}+\mathbf{u}(\mathbf{X})$ after the solid is deformed; and the local deformation of an infinitesimal volume element at position $\mathbf{X}$ in the undeformed microstructure is characterized by the deformation gradient $\mathbf{F}=\partial \mathbf{x} / \partial \mathbf{X}$. In all three phases, the total deformation gradient is decomposed into a plastic part $\mathbf{F}^{p}$ (which accounts for slip in the ferrite and martensite phases, and both slip and the austenite-martensite transformation in the retained austenite phase) together with an elastic part $\mathbf{F}^{e}$ as

$$
\mathbf{F}=\mathbf{F}^{e} \mathbf{F}^{p}
$$

This allows the strain rate $\dot{\boldsymbol{\varepsilon}}=\operatorname{sym}(\partial \dot{\mathbf{x}} / \partial \mathbf{x})$ to be decomposed into elastic and plastic parts as

$$
\dot{\boldsymbol{\varepsilon}}=\dot{\boldsymbol{\varepsilon}}^{e}+\dot{\boldsymbol{\varepsilon}}^{p} \quad \dot{\boldsymbol{\varepsilon}}^{e}=\operatorname{sym}\left(\dot{\mathbf{F}}^{e} \mathbf{F}^{-1}\right) \quad \dot{\boldsymbol{\varepsilon}}^{p}=\operatorname{sym}\left(\mathbf{F}^{e} \dot{\mathbf{F}}^{p} \mathbf{F}^{p-1} \mathbf{F}^{e-1}\right)
$$

In addition, we introduce the elastic Lagrange strain $\mathbf{E}^{e}=\frac{1}{2}\left(\mathbf{F}^{e T} \mathbf{F}^{e}-\mathbf{I}\right)$ to characterize the reversible distortion of the crystal lattice.

The internal forces are quantified by the distribution of Cauchy (true) stress $\boldsymbol{\sigma}$, which satisfies the equilibrium condition $\partial \boldsymbol{\sigma} / \partial \mathbf{x}=\mathbf{0}$, and is related to the elastic strain by

$$
\boldsymbol{\sigma}=\frac{1}{J} \mathbf{F}^{e}\left[\mathbf{C}: \mathbf{E}^{e}\right] \mathbf{F}^{e T}
$$

Here $J=\operatorname{det}(\mathbf{F})$, and $\mathbf{C}$ is the elastic modulus tensor for the material, in its orientation in the undeformed solid. In the martensite and ferrite phases $\mathbf{C}$ is constant. In the retained austenite phase $\mathbf{C}$ evolves with strain as the austenite transforms to martensite, as described in Section 3.5. The governing equations are completed by constitutive equations that relate the plastic strain rate $\dot{\boldsymbol{\varepsilon}}^{p}$ to the stress $\boldsymbol{\sigma}$. Constitutive models for ferrite, martensite and retained austenite are described in more detail in the sections to follow.

\subsection{Constitutive model for ferrite}

In the ferrite phase, plastic flow takes place by shearing on $\{110\}\langle 111\rangle$ slip systems. The slip direction and slip plane normal for slip system $(\alpha)$ are characterized by unit vectors $\mathbf{s}^{(\alpha)}$ and $\mathbf{m}^{(\alpha)}$ in the 
undeformed crystal, which transform to $\mathbf{s}^{*(\alpha)}=\mathbf{F}^{e} \mathbf{s}^{(\alpha)}$ and $\mathbf{m}^{*(\alpha)}=\mathbf{m}^{(\alpha)} \cdot \mathbf{F}^{e-1}$ in the deformed crystal. The plastic strain rate is related to the rate of shearing $\dot{\gamma}^{(\alpha)}$ on the slip systems by

$$
\dot{\boldsymbol{\varepsilon}}^{p}=\sum_{\alpha} \dot{\gamma}^{(\alpha)} \operatorname{sym}\left[\mathbf{s}^{*(\alpha)} \otimes \mathbf{m}^{*(\alpha)}\right]
$$

Constitutive equations must relate $\dot{\gamma}^{(\alpha)}$ to the stresses acting on the slip systems. Recent micropillar experiments and simulations in Chen et al. (2014) have revealed that slip in the ferrite extracted from dual-phase steels does not obey Schmid's law. Such departures from Schmid's law are common in BCC crystals (Weinberger et al., 2012). The shearing rate is therefore characterized by a constitutive relation that accounts for non-Schmid effects as formulated by Weinberger et al. (2012) and detailed in Chen et al. (2014), in which the shearing rate is

$$
\dot{\gamma}^{(\alpha)}=\dot{\gamma}_{0}\left(\frac{\left|\tau^{(\alpha)}\right|}{\mathrm{g}_{*}^{(\alpha)}}\right)^{m} \operatorname{sign}\left(\tau^{(\alpha)}\right)
$$

where

$$
\tau^{(\alpha)}=\mathbf{m}^{*(\alpha)} \cdot \boldsymbol{\sigma} \cdot \mathbf{s}^{*(\alpha)}
$$

is the resolved shear stress on slip system $(\alpha), \dot{\gamma}_{0}$ and $m$ are material parameters, and $\mathrm{g}_{*}^{(\alpha)}$ is modified slip system strength. The slip system strength is given by $\mathrm{g}_{*}^{(\alpha)}=\max \left(\mathrm{g}^{(\alpha)}-\mathrm{g}_{\mathrm{NS}}^{(\alpha)}, 0\right)$, where $\mathrm{g}^{(\alpha)}$ represents classical work hardening resulting from dislocation interactions, while

$$
\mathrm{g}_{\mathrm{NS}}^{(\alpha)}=a_{1} \mathbf{p}^{*(\alpha)} \cdot \boldsymbol{\sigma} \cdot \mathbf{s}^{*(\alpha)}+a_{2} \mathbf{m}^{*(\alpha)} \cdot \boldsymbol{\sigma} \cdot\left(\mathbf{m}^{*(\alpha)} \times \mathbf{s}^{*(\alpha)}\right)+a_{3} \mathbf{p}^{*(\alpha)} \cdot \boldsymbol{\sigma} \cdot\left(\mathbf{p}^{*(\alpha)} \times \mathbf{s}^{*(\alpha)}\right)
$$

is a correction to account for non-Schmid behavior. In Eq. (0), $\left(a_{1}, a_{2}, a_{3}\right)$ are material parameters and $\mathbf{p}^{(\alpha)}$ is a unit vector normal to the $\{110\}$ plane in the zone of $\mathbf{s}^{(\alpha)}$ that makes an angle of $-60^{\circ}$ with the reference plane $\mathbf{m}^{(\alpha)}$ in the undeformed configuration. All the relevant vectors in Eq. (7) are tabulated in Gröger et al. (2008).

The work-hardening resulting from dislocation interactions $\mathrm{g}^{(\alpha)}$ is modeled using the standard crystal plasticity constitutive equations

$$
\dot{g}^{(\alpha)}=\sum_{\beta=1}^{N} h_{\alpha \beta}\left|\dot{\gamma}^{(\beta)}\right|
$$


where following Bassani and $\mathrm{Wu}(1991)$ the self-hardening moduli are given as

$$
\begin{aligned}
& h_{\alpha \alpha}=\left\{\left(h_{0}-h_{s}\right) \operatorname{sech}^{2}\left[\frac{\left(h_{0}-h_{s}\right) \gamma^{(\alpha)}}{\mathrm{g}_{s}-\mathrm{g}_{0}}\right]+h_{s}\right\} \mathrm{G}\left(\gamma^{(\beta)} ; \beta \neq \alpha\right) \\
& \mathrm{G}\left(\gamma^{(\beta)} ; \beta \neq \alpha\right)=1+\sum_{\beta \neq \alpha} f_{0} \tanh \left(\gamma^{(\beta)} / \gamma_{0}\right)
\end{aligned}
$$

and latent hardening moduli are

$$
h_{\beta \alpha}=q h_{\alpha \alpha} \quad \beta \neq \alpha
$$

In Eqs. (0)-(0) $\left\{q, h_{0}, h_{s}, \mathrm{~g}_{0}, \mathrm{~g}_{s}, f_{0}, \gamma_{0}\right\}$ are material parameters. In total this constitutive model has twelve material parameters, which are determined from the data provide by micropillar compression experiments.

\subsection{Constitutive model for martensite}

We idealize the martensite phase present in the as-received material as a hierarchical structure, as described in detail in Ghassemi-Armaki et al. (2013a). At the finest length-scale, martensite consists of a collection of laths with widths of a few tens of nanometers. These are not treated directly in our model, but are idealized as an evolving dislocation density that represents the dislocations in the lath and composing the lath boundaries. The laths are organized within martensite blocks, which we treat as a BCC single crystal with a single orientation (the small misorientations across lath boundaries are neglected). Plastic flow in a block is assumed to take place by crystallographic slip on $\{110\}\langle 111\rangle$ and $\{112\}\langle 111\rangle$ slip systems. The shearing rate on these systems is characterized using Eqs. (0)-(0), but nonSchmid effects are not considered in martensite so $a_{1}=a_{2}=a_{3}=0$. Following Lee et al. (2010b) dislocation hardening is idealized by computing the resistance to slip on each system as

$$
\mathrm{g}^{(\alpha)}=G b \sqrt{\sum_{\beta=1}^{N} a_{\alpha \beta} \rho^{\beta}}
$$

where $a_{\alpha \beta}=\mathbf{m}^{(\alpha)} \cdot \zeta^{(\beta)}$ are constants, with $\zeta^{(\beta)}$ being the line direction of the forest dislocations intersecting the $\alpha^{\text {th }}$ slip plane. The evolution of dislocation density on slip system $(\alpha)$ is given by a widely used dislocation density evolution equation due to Kocks (1976),

$$
\frac{d \rho^{(\alpha)}}{d t}=\left|\dot{\gamma}^{(\alpha)}\right|\left[\frac{1}{b k_{a}} \sqrt{\sum_{\beta}^{n} \rho^{(\beta)}}-\frac{k_{b}}{b} \rho^{\alpha}\right]
$$


where $k_{a}, k_{b}$ are material parameters and $b$ is the Burgers vector. In Eq. (12) the first term on the right side describes the change in obstacle density due to the fact that a certain fraction of the mobile dislocation density has been stored in the crystal after it has moved whereas the second term accounts for the change in dislocation density due to some recovery or rearrangement process that occurs among the dislocations already stored (for additional details see Kocks (1976)). In total, this constitutive equation contains five material parameters (including the initial dislocation density, which is taken equal on all slip systems), which are determined from micropillar compression experiments.

\subsection{Constitutive model for retained austenite}

We next turn to describing our constitutive model for retained austenite. Deformation in retained austenite is more complex than in either ferrite or martensite. In its initial state, the austenite is an FCC single crystal; deformation can proceed by shearing on its slip systems or/and include a martensitic transformation at some critical stress or strain. The martensitic transformation involves nucleation and growth of martensite variants within the austenite matrix. The variants of martensite have identical crystal lattices but are oriented differently with respect to the austenite lattice. There are three possible variants of martensite for the cubic-to-tetragonal martensitic transformation, and in general at least two variants must form simultaneously to ensure compatibility with the parent austenite phase. We focus our attention on transformations involving two variants (Suiker and Turteltaub, 2005, Turteltaub and Suiker, 2005, Turteltaub and Suiker, 2006). The crystallographic theory of martensitic transformation (Ball and James, 1989, Bhattacharya, 1993, Hane and Shield, 1998) shows that the cubic-to-tetragonal martensitic transformation occurs along well defined transformation systems. The $(i)^{\text {th }}$ transformation system is characterized by a unit vector $\mathbf{n}^{(i)}$ normal to the habit plane together with a vector $\gamma_{T} \mathbf{b}^{(i)}$, where $\mathbf{b}^{(i)}$ is a unit vector that lies in the plane of transformation or habit plane and $\gamma_{T}$ is the magnitude of the transition strain. The transformation results in a deformation gradient $\mathbf{F}^{T}=\gamma_{T} \mathbf{s} \otimes \mathbf{n}$ (Anand and Gurtin, 2003). Martensitic transformation along a transformation system $\left(\gamma_{T} \mathbf{b}^{(i)}, \mathbf{n}^{(i)}\right)$ results in the formation of a pair of the martensite variants as schematically shown in Fig. 6. Each pair of martensite variants may form by one of 8 possible transformation systems, so that a total of 24 transformation systems exist for the particular martensitic transformation under consideration. All these 24 transformation systems are listed in Suiker and Turteltaub (2005), Turteltaub and Suiker (2005). 
After the transformation begins, the microstructure consists of a two-phase mixture of untransformed austenite and martensite variants, as illustrated schematically in Fig. 6. We focus our attention at a length scale larger than the length scale of the fine phase mixture of the phases. Hence, we approximate the collective behavior of the composite microstructure using a homogenized constitutive equation, in which the evolving martensite volume fraction is a state variable, following the approach similar to Anand and Gurtin (2003). Specifically, we denote the volume fraction of austenite in the composite microstructure by $\xi_{A}$ (with $\xi_{A}=1$ at time $t=0$ ), and denote the volume fraction of martensite resulting from transformation on the $(i)^{\text {th }}$ system by $\xi^{(i)}$. We also introduce the total martensite volume fraction

$$
\xi_{M}=\sum_{i=1}^{24} \xi^{(i)}
$$

In the composite microstructure, three processes may contribute to the plastic strain: (i) slip in the untransformed austenite; (ii) slip in the product martensite; and (iii) the irreversible transformation strain associated with the austenite-to-martensite transformation. Accordingly, the plastic strain rate is divided into three contributions

$$
\dot{\boldsymbol{\varepsilon}}^{p}=\dot{\boldsymbol{\varepsilon}}^{p a}+\dot{\boldsymbol{\varepsilon}}^{p m}+\dot{\boldsymbol{\varepsilon}}^{p t}
$$

where $\left(\dot{\boldsymbol{\varepsilon}}^{p a}, \dot{\boldsymbol{\varepsilon}}^{p m}, \dot{\boldsymbol{\varepsilon}}^{p t}\right)$ are the contributions to the plastic strain rate from slip in the untransformed austenite; slip in the product martensite; and the austenite-martensite transformation, respectively. We approximate the stress state in the composite by assuming that the fine-phase microstructure is subjected to the same stress.

The plastic flow in the austenite phase is assumed to take place by shearing on $\{111\}\langle 110\rangle$ slip systems. The contribution to the plastic strain rate is taken to be

$$
\dot{\boldsymbol{\varepsilon}}^{p a}=\xi_{A} \sum_{\alpha} \dot{\gamma}^{(\alpha)} \operatorname{sym}\left[\mathbf{s}^{*(\alpha)} \otimes \mathbf{m}^{*(\alpha)}\right]
$$

where the sum is taken over the 12 FCC slip systems. The shearing rate is calculated using the standard viscoplastic Schmid law

$$
\dot{\gamma}^{(\alpha)}=\dot{a}_{0}\left(\frac{\left|\tau^{(\alpha)}\right|}{g^{(\alpha)}}\right)^{m} \operatorname{sign}\left(\tau^{(\alpha)}\right)
$$

where $\tau^{(\alpha)}=\mathbf{m}^{*(\alpha)} \cdot \boldsymbol{\sigma} \cdot \mathbf{s}^{*(\alpha)}$, is the resolved shear stress acting on the slip system, $g^{(\alpha)}$ is the slip system strength, and $\dot{a}_{0}$ and $m$ are material parameters. The strength of each slip system evolves according to 


$$
\dot{g}^{(\alpha)}=\sum_{\beta} h_{\alpha \beta}\left|\dot{\gamma}^{(\beta)}\right|
$$

and the hardening moduli following Peirce et al. (1982) are given as

$$
\begin{gathered}
h_{\alpha \alpha}=h_{0} \operatorname{sech}^{2}\left[\frac{h_{0} \bar{\gamma}}{\mathrm{g}_{s}-\mathrm{g}_{0}}\right] \quad \bar{\gamma}=\sum_{\alpha} \int_{0}^{t}\left|\dot{\gamma}^{(\alpha)}\right| d t \\
h_{\alpha \beta}=q h_{\alpha \alpha}(\beta \neq \alpha)
\end{gathered}
$$

where, $\left\{h_{0}, \mathrm{~g}_{o}, \mathrm{~g}_{s}, q\right\}$ are material parameters.

The plastic strain rate in the product martensite phase is approximated by setting

$$
\dot{\boldsymbol{\varepsilon}}^{p m}=\xi_{M} \sum_{\alpha} \dot{\gamma}^{(\alpha)} \operatorname{sym}\left[\mathbf{s}^{*(\alpha)} \otimes \mathbf{m}^{*(\alpha)}\right]
$$

where the slip directions and slip plane normals are taken to be $\{110\}\langle 111\rangle$ and $\{112\}\langle 111\rangle$ slip systems for a BCC crystal with the same orientation as the parent austenite grain. Although individual martensite variants are oriented differently with respect to the parent austenite lattice, the martensitic transformation along a transformation system in the current formulation results in a pair of martensite variants. In general transformation occurs along multiple transformation systems resulting in one or more pairs of martensite variants. As a result, misorientation between the parent austenite lattice and collective orientation of the martensite variants is within few degrees and hence are ignored here for simplicity.

The shearing rate in the martensite is characterized using the same constitutive equation used to model the initial martensite phase, described in Section 3.4. However, the properties of the martensite formed after martensitic transformation differs from those of the martensite present in the initial microstructure.

The austenite-martensite transformation also contributes to the strain rate in the retained austenite phase. We take its contribution to the strain rate to be

$$
\dot{\boldsymbol{\varepsilon}}^{p t}=\sum_{i=1}^{24} \dot{\xi}^{(i)} \gamma_{T} \mathbf{b}^{*(i)} \otimes \mathbf{n}^{*(i)}
$$

where the sum is taken over the 24 possible transformation systems, and $\mathbf{b}^{*(i)}=\mathbf{F}^{e} \mathbf{b}^{(i)}, \mathbf{n}^{*(i)}=\mathbf{n}^{(i)} \cdot \mathbf{F}^{e-1}$ are the shearing direction and habit plane normal in the deformed crystal. The transformation rate $\dot{\xi}^{(i)}$ on a transformation system $(i)$ is given as 


$$
\dot{\xi}^{(i)}=\left\{\begin{array}{cc}
\dot{\xi}_{0} \mid \frac{\tau^{(i)}}{\tau_{0}}-1 & \text { for } \frac{\tau^{(i)}}{\tau_{0}}>1 \text { and } \xi_{M}<1 \\
0 & \text { otherwise }
\end{array}\right.
$$

Here $\tau^{(i)}$, the resolved stress on the $(i)^{\text {th }}$ transformation system, is the work conjugate to the $\dot{\xi}^{(i)}$ based on the microforce balance discussed in Anand and Gurtin (2003). The resolved shear stress is

$$
\tau^{(i)}=\mathbf{n}^{*(i)} \cdot \boldsymbol{\sigma} \cdot \mathbf{b}^{*(i)}
$$

The constitutive relation in Eq. (0) contains two material parameters: $\dot{\xi}_{0}$ is the reference transformation rate, and $\tau_{0}$ is the reference transformation strength. All transformation systems are assumed to have the same properties. Once the transformation criterion is satisfied for a transformation system $(i)$, the quantity $\left|\tau^{(i)} / \tau_{0}-1\right|$ is the excess driving force for martensitic transformation on that particular transformation system.

The constitutive model for the retained austenite phase is completed by specifying the evolution of its elastic modulus with martensite volume fraction, which is expressed as

$$
\mathbf{C}=\left(1-\xi_{M}\right) \mathbf{C}_{R A}+\xi_{M} \mathbf{C}_{M}
$$

where $\mathbf{C}_{R A}$ and $\mathbf{C}_{M}$ are the moduli of austenite (FCC) and martensite (approximated as BCC), with crystallographic orientation aligned with that of the parent austenite phase. Note that the martensite modulus should be interpreted as the homogenized effective modulus of all the martensite variants present in the microstructure.

\subsection{Constitutive model calibration}

The constitutive equations described in the preceding sections contain a large number of material properties, which must be determined experimentally. The properties of the ferrite and martensite phases can be determined directly from the micropillar compression experiments described in Section 2, following the procedure described in detail in Ghassemi-Armaki et al. (2013a), Chen et al. (2014). The tests on ferrite micropillars can be regarded, approximately, as uniaxial compression tests on single crystal specimens with a known initial orientation with respect to the loading direction and containing the relevant partitioned solute content and dislocation density. By obtaining stress-strain measurements for several specimens, it is possible to determine values for the initial flow stress, the hardening rate as well as the parameters governing the non-Schmid nature of slip. Interpreting the experiments is complicated 
somewhat by the anisotropy of slip in the single crystal, which leads to a complex, inhomogeneous distribution of strain and stress in the pillar. To correct for these effects, material parameters are extracted using an iterative process in which full 3D finite element simulations of each micropillar compression experiment are performed, and the material parameters in the simulation are progressively adjusted until the best fit to the experimental data has been obtained. This procedure is described in detail in Chen et al. (2014). The resulting properties of the ferrite phase are listed in Table 1. The measured and the predicted stress-strain curves of ferrite micropillars with three different orientations are compared in Figure 8(a) and good agreement is noted.

A similar procedure is used to determine parameters for the martensite phase initially present in the microstructure. As discussed in Ghassemi-Armaki et al. (2013a), Chen et al. (2014), the compression response of the specimens depends on their size, and exhibits considerable scatter if the specimen diameter lies below a critical value $(\sim 1 \mu \mathrm{m})$. Specimens with diameter exceeding this value show one of two types of response, depending on their microstructure. If the specimens contain several martensite blocks, constraints between the martensite block cause them to deform in multiple slip, which causes the pillars to strain harden. If they contain only one martensite block, they deform in single slip, and display nearly elastic-perfectly plastic behavior. By fitting simulation predictions to each type of response, it is possible to determine the initial flow strength of the martensite (which is determined from non-hardening pillars), as well as its latent and self-hardening behavior (which is determined from the response of pillars that harden). The properties of martensite are listed in Table 1, and Fig. 8(b) compares the measured and predicted stress-strain curves for martensite micropillars containing both a single and multiple martensite blocks.

The retained austenite grains present in the Q\&P980 steel are too small to be characterized using micropillar compression tests. Instead, the properties of retained austenite are determined indirectly, by fitting the predicted stress-strain response of a three dimensional representative volume element of the Q\&P980 microstructure to the measured bulk uniaxial tensile stress-strain behavior, and by fitting the predicted volume fraction of transformed austenite in the RVE to EBSD measurements. The fitting process involves three steps. First, uniaxial tensile stress-strain curves are computed for homogeneous, isotropic (random polycrystalline) RVEs of pure ferrite and martensite, using the calibrated constitutive equations for each phase. To obtain a rough initial estimate of the contribution to the stress that is provided by the retained austenite phase, we suppose that the behavior of the representative volume element of Q\&P980 can be predicted using the Voigt average

$$
\boldsymbol{\sigma}(\boldsymbol{\varepsilon})=f_{F} \boldsymbol{\sigma}^{F}(\boldsymbol{\varepsilon})+f_{M} \boldsymbol{\sigma}^{M}(\boldsymbol{\varepsilon})+f_{R A} \boldsymbol{\sigma}^{R A}(\boldsymbol{\varepsilon})
$$


where $\boldsymbol{\sigma}^{F}, \boldsymbol{\sigma}^{M}, \boldsymbol{\sigma}^{R A}$ are the stresses in a homogeneous specimen of ferrite, martensite and retained austenite at a prescribed uniaxial strain, and $\left(f_{F}, f_{M}, f_{R A}\right)$ are the volume fractions of the ferrite, martensite and retained austenite phases, respectively. The difference between the predictions of Eq. (0) with $\boldsymbol{\sigma}^{R A}=\mathbf{0}$ and the actual uniaxial stress-strain response provides an estimate of the contribution to the total stress from retained austenite.

An initial estimate for the properties of the retained austenite is then obtained by fitting the predicted behavior of a homogeneous specimen of retained austenite with an isotropic random distribution of grain orientations to $\sigma^{R A}$, and fitting simultaneously the volume fraction of transformed austenite as a function of strain to the EBSD measurements described in Section 2. For this purpose, the average volume fraction of transformed austenite in the RVE is estimated as

$$
\mathrm{X}_{M}{ }^{\mathrm{RVE}}=\frac{1}{V_{R A}} \sum_{\text {Elements }} \xi_{M}^{(k)} V_{e l}^{(k)}
$$

where $\xi^{(k)}$ is the martensite volume fraction at the centroid of the $k^{\text {th }}$ element; $V_{e l}^{(k)}$ is the volume of the $k^{\text {th }}$ element; and $V_{R A}$ is the total volume of the elements comprised of retained austenite in the mesh. The corresponding volume fraction of transformed austenite in the experiments is estimated from the EBSD measurements as

$$
X_{M}^{\operatorname{Exp}}=1-\frac{f_{R A}^{\text {current }}}{f_{R A}^{\text {initial }}}
$$

where $f_{R A}^{\text {current }}$ and $f_{R A}^{\text {initial }}$ are the current and initial volume fractions of retained austenite in the micrograph. Finally, once an approximate value for the properties of the retained austenite has been found, the estimate is further refined by fitting the predicted uniaxial stress-strain curve and transformed martensite volume fraction in a full 3D representative volume element of the Q\&P980 steel to the experimental data. The final values for material parameters are listed in Table 1.

With the properties given in Table 1, calculations predict that a homogeneous, isotropic volume element of pure austenite phase (assuming no phase transformation occurs) has flow strength of $\sim 400 \mathrm{MPa}$. Similarly a comparison of the constitutive material model parameters of existing martensite and new martensite formed due to martensitic transformation in Table 1 suggests that new martensite is stronger than the existing martensite. The initial dislocation density in new martensite is roughly 1.6 times that of existing martensite. Calculations predict that a homogeneous volume element of existing martensite has flow strength slightly over $900 \mathrm{MPa}$ whereas the flow strength of new martensite is roughly $1400 \mathrm{MPa}$. 
The predicted and measured macroscopic flow behavior of Q\&P980 steel and transformed austenite volume fraction in the same are compared in the next section, which includes a more detailed discussion.

\section{Results and Discussion}

With calibrated constitutive equations for the three phases in Q\&P980 at hand, the simulations can now be used to predict both the macroscopic behavior of the microstructure, and the nature of the internal deformation mechanisms that give rise to its strength and ductility.

\subsection{Macroscopic stress-strain curves and evolution of retained austenite volume fraction}

The measured and predicted macroscopic uniaxial tensile stress-strain curves for Q\&P980 are compared in Fig. 9(a). Since necking cannot be predicted by our computations which (by construction) impose a uniform macroscopic strain on the representative volume element, results are shown for applied strains up to $15 \%$, which corresponds to the onset of diffuse necking in the experiments. Predictions are shown for two volume fractions of retained austenite, $f_{R A}=0.1$ and 0.08 , and for each case, three martensite volume fractions, $f_{M}=0.42,0.44$, and 0.46 are considered. The calculations show that small variations in the volume fraction of the phases do not significantly influence the stress-strain behavior.

Figure 9(b) compares the predicted and measured evolution of the normalized work-hardening rate, $(1 / \sigma) d \sigma / d \varepsilon$ where $\sigma$ and $\varepsilon$ are the true stress and strain, respectively. The work-hardening rate decreases rapidly for $\varepsilon<0.01$ and subsequently decreases slowly. For reference, Considère's criterion for tensile instability or necking, $(1 / \sigma) d \sigma / d \varepsilon=1$, is marked as a dashed horizontal line in Fig. 9(b). The figure shows that the simulations are able to capture both the strength and hardening rate of the microstructure; and moreover illustrate that the Considère's criterion predicts the onset of diffuse necking remarkably well.

Figure 10 compares the measured and predicted average volume fraction of the martensite formed within the retained austenite (computed using Eqs. (0) and (0)). The average volume fraction of the new martensite evolves approximately linearly with the macroscopic nominal strain. At macroscopic nominal strain of $15 \%$, approximately $70 \%$ of the retained austenite has transformed to martensite, leaving $30 \%$ of the initial retained austenite in the material. These observations are comparable to the results of X-ray diffraction measurements of the austenite-martensite transformation in a similar Q\&P980 steel by Wang 
and Speer (2013). Small variations in the initial volume fractions of the phases in the microstructure do not significantly alter the evolution of martensite volume fraction with strain.

In addition, our simulations provide a detailed picture of the austenite-martensite transformation within the microstructure. Fig. 11(a) illustrates the distribution of martensite volume fraction in each of the retained austenite grains in the microstructure at a macroscopic nominal strain of $15 \%$. A considerable variation in martensite volume fraction develops both among grains, and within individual grains. The variation in martensite volume fraction among grains is caused by variations in the crystallographic orientation of each grain as well as due to the difference in the surrounding matrix. The variation within the grains is a consequence of the heterogeneous stress and strain state that develops within the grain. Note that simulations predict that several particles are partially transformed to martensite, in qualitative agreement with the experimental results described in Section 2.

The distribution of deformation-induced martensite volume fraction is quantified in more detail in Fig. 11(b), which shows the predicted histograms of $\xi_{M}$ at macroscopic nominal strains of 5\%,10\% and $15 \%$. At $5 \%$ strain a comparatively narrow distribution of martensite volume fraction is observed, but the distribution progressively broadens as the strain is increased, with some regions reaching $100 \%$ martensite volume fraction at $10 \%$ strain. At strains approaching $15 \%$ a bi-modal distribution starts to develop in which a significant fraction of the retained austenite is fully transformed, and which contains a second peak at approximately $70 \%$ volume fraction.

Histograms showing the size of the retained austenite grains modeled in the initial microstructure, as well as after $10 \%$ and $15 \%$ macroscopic nominal strain are shown in Fig. 11(c). The size of each retained austenite grain was estimated by calculating the total volume of all the elements within a retained austenite grain with martensite volume fraction $\xi_{M}<0.6$ (i.e. we assume that if an element within a retained austenite grain has $\xi_{M}>0.6$, then the element is martensite rich and not counted as FCC phase). The histograms were normalized by the volume of the largest austenite grain present in the simulation cell in its initial state $V_{(\text {norm })}$. The results show that the size of the retained austenite grains decreases with increasing macroscopic tensile deformation in agreement with the experimental observations described in Section 2. Since the constitutive model of retained austenite (Section 3.5) does not inherently consider any size effects, the results in Fig. 11(c) are partly a consequence of the fact that small grains tend to be shielded from stress and hence transform later than the larger grains, and partly because partially transformed retained austenite grains appear as smaller grains as the deformation proceeds. 


\subsection{Strain and Stress Partitioning}

It is instructive to determine the contribution to the plastic strain from each of the phases present in the steel at various strain levels. To this end, we define the plastic equivalent strain rate in each phase through the sum

$$
\dot{\varepsilon}_{e p}^{\text {(Phase) }}=\frac{1}{V_{(\text {Phase })}} \sum_{\text {El } \in \text { Phase }} \dot{\varepsilon}_{e p}^{(k)} V_{e l}^{(k)}
$$

where the sum is taken over all the elements within one of the three phases; $V_{(\text {Phase })}$ is the total volume of the phase present in the microstructure, $V_{e l}^{(k)}$ is the volume of the $k^{\text {th }}$ element, and $\dot{\varepsilon}_{e p}^{(k)}$ is the plastic equivalent strain rate computed at the centroid of the $k^{\text {th }}$ element. The plastic equivalent strain in each phase may then be computed through the time integral of Eq. (0). We then define the fractional contribution to the total plastic equivalent strain rate and plastic equivalent strain from each phase as the ratio of $\dot{\varepsilon}_{e p}^{\text {(Phase) }}$ to the total plastic equivalent strain rate and plastic equivalent strain in all three phases. The plastic strain rate and plastic strain fractions contributed by the three phases are shown as functions of the applied strain in Fig. 12, for a microstructure with martensite and retained austenite volume fractions $f_{M}=0.44$ and $f_{R A}=0.1$. As shown in the figures, retained austenite yields at an early stage and hence initially contributes almost all the plastic strain as well as strain rate. Following the yielding of ferrite the contribution to plastic strain and strain rate of retained austenite decreases rapidly, while that of ferrite increases rapidly. With further deformation, martensite yields and following the yielding of martensite, there is a sudden drop in the fraction of plastic strain and strain rate of ferrite. After this sudden drop, the fraction of plastic strain and strain rate in ferrite phase stays nearly constant, while the contribution of martensite increases slowly and that of retained austenite decreases slowly. At high macroscopic nominal strains, the dominant contribution to plasticity is due to ferrite.

In the same way, the contribution from each phase to the total stress in the microstructure can be computed as

$$
\sigma_{i j}^{(\text {Phase })}=\frac{1}{V_{(\text {Phase })}} \sum_{\text {ElePhase }} \sigma_{i j}^{(k)} V_{e l}^{(k)}
$$

The contribution to the total stress parallel to the extension direction, $\sigma_{11}$, from each phase is shown as a function of macroscopic strain in Fig. 13(a), for a microstructure with martensite and austenite volume 
fractions $f_{M}=0.44$ and $f_{R A}=0.1$. These results can be interpreted approximately as the stress components that would be extracted from a diffraction measurement of the corresponding lattice strains in each phase. Similarly the evolution of von Mises effective stress, $\sigma_{\text {mises }}$, with von Mises effective strain, $\varepsilon_{\text {mises }}$, in each phase is shown in Fig. 13(b). The evolution of $\sigma_{\text {mises }}$ with $\varepsilon_{\text {mises }}$ can be interpreted as the true stress-strain response of each phase inside the RVE.

The retained austenite phase yields at $\sim 350 \mathrm{MPa}$, the ferrite phase yields around $400 \mathrm{MPa}$ and the martensite phase yields around 900MPa. At the yield point, the values of $\sigma_{11}$ and $\sigma_{\text {mises }}$ are roughly the same for all three phases. After all three phases yield, the evolution of $\sigma_{11}$ with macroscopic strain and the evolution of $\sigma_{\text {mises }}$ with $\varepsilon_{\text {mises }}$ differ in all three phases. In the martensite phase $\sigma_{11}$ is less than $\sigma_{\text {mises }}$ whereas in the ferrite phase $\sigma_{11}$ is greater than $\sigma_{\text {mises }}$. In the retained austenite phase $\sigma_{11}$ is greater than $\sigma_{\text {mises }}$ until a macroscopic strain of $\sim 6 \%$, beyond which $\sigma_{11}$ is less than $\sigma_{\text {mises }}$. This shows the development of complicated internal stress states in the material even under applied uniaxial strain. The ferrite phase shows work-hardening until about $\sigma_{11} \approx 750 \mathrm{MPa}$ or $\sigma_{\text {mises }} \approx 680 \mathrm{MPa}$, and the martensite phase exhibits work-hardening until about $\sigma_{11} \approx 1050 \mathrm{MPa}$ or $\sigma_{\text {mises }} \approx 1150 \mathrm{MPa}$ and thereafter, the work-hardening in these two phases is negligible. On the other hand, the retained austenite phase shows continuous work-hardening with progressive tensile straining. This implies that the retained austenite phase provides the dominant contribution to the macroscopic work-hardening at large strains.

\subsection{The role of retained austenite in controlling macroscopic response}

The role of retained austenite in controlling the overall response of Q\&P980 is of particular interest. To this end, we have created several 'virtual materials' to probe the influence of the retained austenite on the uniaxial stress-strain response of the microstructure. First, we have computed flow curves for model materials in which the retained austenite was removed and replaced with either ferrite, an equal volume fraction of ferrite and pre-existing martensite, or with pre-existing martensite. The results are displayed in Fig. 14. The flow curves for materials which contain no retained austenite have a higher initial yield stress and exhibit negligible work-hardening following macroscopic yielding. This shows that retained austenite decreases the flow strength at low applied strains, and thereafter increases the flow stress by slow but continuous work-hardening. This improvement in strain hardening would be expected to delay the onset of localization, possibly leading to better ductility. 
It is also of interest to determine the role played by each of the three possible mechanisms of deformation (slip in austenite; slip in martensite; and the strain contributed by the transformation) that occur in the retained austenite phase. This cannot be done experimentally, but in simulations it is possible to create materials in which one or more deformation mechanism does not take place. For example, Fig. 15 shows predicted stress-strain curves and the fraction of transformed austenite in virtual materials in which (i) both austenite and martensite slip is suppressed, so the austenite to martensite transformation provides the only contribution to the strain (this curve is labeled TRANS); (ii) slip in the austenite phase is suppressed, so that martensite slip and the transformation process provide contributions to the strain (the curve is labeled TRANS+MART); and (iii) all three processes contribute to the deformation. The first case significantly over predicts both the flow stress and the volume fraction of the new martensite. In this case the computation was terminated because of excessive stresses in the product martensite phase. If the martensite is permitted to deform plastically, the stress levels are reduced as well as the transformation rate is also slightly decreased, but this approximation still over predicts the initial flow curve as well as the transformation. This clearly shows that the plasticity in austenite matrix coupled with the transformation induced plasticity and the plasticity of the new martensite is needed to achieve the necessary accommodation between the phases present in retained austenite grain during mechanical deformation.

\subsection{Statistics of stress and strain distributions}

We now examine the internal stress and strain distributions in the microstructure in more detail, with a particular focus on the statistics of stress and strain measures that are known to be related to the nucleation and growth of cracks and voids. To this end, Fig 16 shows the cumulative distribution function (CDF) of the maximum principal stress (which is related to nucleation of cracks (Ritchie et al., 1973)), the plastic equivalent strain (which is related to nucleation of voids in a ductile matrix (Chu and Needleman, 1980)), and the stress triaxiality (the ratio of the first and second stress invariants) which is related to void growth in ductile fracture (Benzerga and Leblond, 2010) for a microstructure with $f_{M}=0.44$ and $f_{R A}=0.1$ at a macroscopic nominal strain of $15 \%$. The plots can be interpreted as displaying the probability that a stress or strain measure will exceed a given value on the horizontal axis. From Fig. 16(a), it is clear that the probability that the maximum principal stress will exceed a given threshold is

highest in the retained austenite phase. There is a $10^{-3}$ probability that the maximum principal stress in retained austenite will exceed $2.5 \mathrm{GPa}$. It is worth noting that at $15 \%$ strain, roughly $70 \%$ of the retained 
austenite phase in the material has undergone martensitic transformation and the new martensite is stronger than the existing martensite, which accounts for the high stress levels. In contrast, the probability that the plastic equivalent strain and stress triaxiality will exceed any given threshold is highest in ferrite. The stress triaxiality in ferrite can go up to 2 with a finite probability of $10^{-3}$. These results suggest that after $15 \%$ macroscopic tensile strain, the probability of void nucleation is highest in the ferrite phase, whereas the probability of crack nucleation is highest in the retained austenite phase.

Similarly, to assess the susceptibility of the interfaces to fracture and void nucleation, we have examined the statistical variations of stresses adjacent to each type of interface present in the material. Stresses near the interfaces were computed by first finding all the nodes in the finite element mesh that lie on each interface of interest, and then averaging the stresses in the elements connected to this node. Fig. 17 shows cumulative distributions of principal stress, equivalent plastic strain, and stress triaxiality at the three different bi-material interfaces and at one possible tri-material interface that are present in the microstructure, for a RVE with $f_{M}=0.44$ and $f_{R A}=0.1$ at a macroscopic nominal strain of $15 \%$. As shown in Fig. 17(a), the interfaces between retained austenite and pre-existing martensite have the highest probability that the maximum principal stress will exceed a given value. In contrast, the interfaces between ferrite and martensite have the highest probability that the equivalent plastic strain and stress triaxiality will exceed a critical value. These results suggest that at $15 \%$ strain the probability of void nucleation is highest at the ferrite-martensite interphase boundary, while the probability of crack nucleation is highest at the retained austenite-martensite interphase boundary.

The high stress triaxiality values predicted in the microstructure provide a qualitative explanation for the comparatively poor resistance of Q\&P980 (and other steels with similar microstructures) to ductile fracture. In a homogeneous material, the stress triaxiality always (prior to any localization) has a value of 1/3, which does not significantly enhance void nucleation and growth (Benzerga and Leblond, 2010). In the complex microstructure of AHSS, constraints between the soft and hard phases tend to generate high levels of stress triaxiality both in the ferrite phase and at the interphase boundaries involving ferrite, especially ferrite-martensite. Simulations also suggest that the retained austenite phase plays two competing roles: it improves strain hardening and therefore delays localization and necking; but at the same time it tends to increase the levels of stress present in the microstructure. A similar trade-off was postulated by Jacques et al. (2001b) by comparing two multiphase TRIP-assisted steels with different initial retained austenite volume fraction and their stability. 


\section{Conclusions}

The micromechanics of plastic deformation and phase transformation in a three-phase (ferrite, martensite and retained austenite) advanced high strength steel (Baosteel Q\&P980) have been analyzed both experimentally and using 3-D microstructure based finite element calculations. In the experiments, the macroscopic flow behavior and volume fraction of product martensite resulting from the deformationinduced martensitic transformation of austenite were measured. Micropillar compression of specimens, extracted from the ferrite and martensite phases, provided stress-strain curves that was directly used to calibrate appropriate crystal plasticity constitutive models for these two phases. For retained austenite a new constitutive model within the frame work of crystal plasticity was developed that accounts for contributions to the strain rate from the austenite-martensite transformation, as well as slip in both the austenite and product martensite. In the 3-D microstructure based finite element calculations the ferrite, martensite and retained austenite are discretely modeled. The constitutive parameters for the retained austenite were determined by fitting the predicted flow stress and transformed austenite volume fraction in the 3D microstructure to experimental measurements.

The principal conclusions of our study are:

1. The macroscopic stress-strain curve for Q\&P980 shows initial yielding at $400 \mathrm{MPa}$ followed by steep work hardening until about 800MPa.

2. The flow strength of the ferrite phase in the steel is slightly above $400 \mathrm{MPa}$. The orientation dependence of the flow stress in the ferrite phase shows significant departures from Schmid's law. The properties of ferrite are similar to those measured previously for 980MPa grade dualphase (ferrite-martensite) steels in Chen et al. (2014).

3. The flow strength of martensite phase in the steel is slightly over $900 \mathrm{MPa}$. The measured flow strength is comparable to martensite phase in a $980 \mathrm{MPa}$ grade dual-phase steel (Chen et al. (2014)) with a lower carbon content relative to the Q\&P980 steel examined in this study. This suggests that a significant amount of carbon in Q\&P980 steel partitions to the retained austenite during heat treatment.

4. Our calculations show that when modeling retained austenite phase, it is necessary to account for plasticity in the untransformed austenite, transformation induced plasticity, and plasticity in the product martensite to correctly predict the macroscopic flow behavior of Q\&P980 and the evolution of deformation-induced martensite volume fraction with strain.

5. The calibrated constitutive model of retained austenite suggests that the flow strength of austenite (not undergoing martensitic transformation) is $\sim 400 \mathrm{MPa}$ and that of the new martensite formed 
during deformation is $\sim 1400 \mathrm{MPa}$. The overall yielding of retained austenite phase (undergoing both plasticity and transformation) in the steel occurs at $\sim 350 \mathrm{MPa}$.

6. The transformation of retained austenite to martensite progresses roughly linearly with macroscopic tensile strain. At $\sim 3 \%$ macroscopic tensile strain roughly $10 \%$ of retained austenite transforms into martensite and at this point, stress parallel to the tensile loading direction $\sigma_{11}$ in retained austenite is $\sim 750 \mathrm{MPa}$ and von Mises effective stress $\sigma_{\text {mises }}$ is $\sim 700 \mathrm{MPa}$; at $15 \%$ strain, $70 \%$ of retained austenite transforms into martensite and $\sigma_{11}$ is slightly over $1250 \mathrm{MPa}$ and $\sigma_{\text {mises }}$ is just over $1400 \mathrm{MPa}$.

7. The calculations show that the extent of deformation-induced martensitic transformation significantly varies both among grains, and within an individual grain; this is reflected in the increase in the fine-sized retained austenite grains with increasing macroscopic tensile deformation in agreement with experimental observations.

8. Simulations on virtual materials suggest that the retained austenite phase tends to decrease the initial yield stress of the steel by $\sim 6-7 \%$, and subsequently increases the rate of strain hardening. This enhanced strain hardening is likely to delay localization and necking in tensile specimens.

9. Simulations were used to compute statistical distributions of maximum principal stress, stress triaxiality, and equivalent plastic strain both within the bulk phases, and at interfaces between phases. The results suggest that the driving force for void nucleation is greatest in the ferrite phase, whereas the driving force for crack nucleation is greatest in the retained austenite phase. In addition, it was found that ferrite-martensite interfaces experience the greatest driving forces for void nucleation, whereas driving forces for crack nucleation are greatest on interfaces that include the retained austenite (i.e. ferrite/retained austenite and martensite/retained austenite interfaces).

\section{Acknowledgments}

The computational work in this paper was supported by General Motors through the GM/Brown Collaborative Research Laboratory on Computational Materials Research. The experiments were supported by the Department of Energy National Energy Technology Laboratory under Award Number(s) DE-EE0005976.

This report was prepared as an account of work sponsored by an agency of the United States Government. Neither the United States Government nor any agency thereof, nor any of their employees, makes any warranty, express or implied, or assumes any legal liability or responsibility for the accuracy, 
completeness, or usefulness of any information, apparatus, product, or process disclosed, or represents that its use would not infringe privately owned rights. Reference herein to any specific commercial product, process, or service by trade name, trademark, manufacturer, or otherwise does not necessarily constitute or imply its endorsement, recommendation, or favoring by the United States Government or any agency thereof. The views and opinions of authors expressed herein do not necessarily state or reflect those of the United States Government or any agency thereof.

\section{References}

Anand, L. \& Gurtin, M. E. 2003. Thermal effects in the superelasticity of crystalline shape-memory materials. Journal of the Mechanics and Physics of Solids, 51, 1015-1058.

Ball, J. M. \& James, R. D. 1989. Fine phase mixtures as minimizers of energy. Analysis and Continuum Mechanics. Springer.

Bassani, J. L. \& Wu, T.-Y. 1991. Latent hardening in single crystals II. Analytical characterization and predictions. Proceedings of the Royal Society of London. Series A: Mathematical and Physical Sciences, 435, 21-41.

Benzerga, A. \& Leblond, J.-B. 2010. Ductile fracture by void growth to coalescence. Advances in Applied Mechanics, 44, 169-305.

Bhattacharya, K. 1993. Comparison of the geometrically nonlinear and linear theories of martensitic transformation. Continuum Mechanics and Thermodynamics, 5, 205-242.

Chen, P., Ghassemi-Armaki, H., Kumar, S., Bower, A., Bhat, S. \& Sadagopan, S. 2014. Microscalecalibrated modeling of the deformation response of dual-phase steels. Acta Materialia, 65, 133149.

Cheng, S., Wang, X.-L., Feng, Z., Clausen, B., Choo, H. \& Liaw, P. K. 2008. Probing the characteristic deformation behaviors of transformation-induced plasticity steels. Metallurgical and Materials Transactions A, 39, 3105-3112.

Cherkaoui, M., Berveiller, M. \& Sabar, H. 1998. Micromechanical modeling of martensitic transformation induced plasticity (TRIP) in austenitic single crystals. International Journal of Plasticity, 14, 597-626.

Choi, K. S., Liu, W. N., Sun, X. \& Khaleel, M. A. 2009. Microstructure-based constitutive modeling of TRIP steel: Prediction of ductility and failure modes under different loading conditions. Acta Materialia, 57, 2592-2604. 
Choi, S.-H., Kim, E.-Y., Woo, W., Han, S. \& Kwak, J. 2013. The effect of crystallographic orientation on the micromechanical deformation and failure behaviors of DP980 steel during uniaxial tension. International Journal of Plasticity, 45, 85-102.

Chu, C. \& Needleman, A. 1980. Void nucleation effects in biaxially stretched sheets. Journal of Engineering Materials and Technology, 102, 249-256.

Cong, Z., Jia, N., Sun, X., Ren, Y., Almer, J. \& Wang, Y. 2009. Stress and strain partitioning of ferrite and martensite during deformation. Metallurgical and Materials Transactions A, 40, 1383-1387.

Dassault Systemes Simulia Corp. 2010. Abaqus User's Manual Version 6.10. Providence (RI, USA).

Delannay, L., Jacques, P. \& Pardoen, T. 2008. Modelling of the plastic flow of trip-aided multiphase steel based on an incremental mean-field approach. International journal of solids and structures, 45, 1825-1843.

Diani, J. \& Parks, D. 1998. Effects of strain state on the kinetics of strain-induced martensite in steels. Journal of the Mechanics and Physics of Solids, 46, 1613-1635.

Edmonds, D., He, K., Rizzo, F., De Cooman, B., Matlock, D. \& Speer, J. 2006. Quenching and partitioning martensite-A novel steel heat treatment. Materials Science and Engineering: A, 438, 25-34.

Fischer, F., Sun, Q.-P. \& Tanaka, K. 1996. Transformation-induced plasticity (TRIP). Applied Mechanics Reviews, 49, 317-364.

Fischer, F., Reisner, G., Werner, E., Tanaka, K., Cailletaud, G. \& Antretter, T. 2000. A new view on transformation induced plasticity (TRIP). International Journal of Plasticity, 16, 723-748.

Ghassemi-Armaki, H., Chen, P., Bhat, S., Sadagopan, S., Kumar, S. \& Bower, A. 2013a. Microscalecalibrated modeling of the deformation response of low-carbon martensite. Acta Materialia, 61, 3640-3652.

Ghassemi-Armaki, H., Maaß, R., Bhat, S., Sriram, S., Greer, J. \& Kumar, K. 2013b. Deformation response of ferrite and martensite in a dual-phase steel. Acta Materialia, 62, 197-211.

Govindjee, S. \& Miehe, C. 2001. A multi-variant martensitic phase transformation model: formulation and numerical implementation. Computer Methods in Applied Mechanics and Engineering, 191, 215-238.

Gröger, R., Racherla, V., Bassani, J. \& Vitek, V. 2008. Multiscale modeling of plastic deformation of molybdenum and tungsten: II. Yield criterion for single crystals based on atomistic studies of glide of $1 / 2<111>$ screw dislocations. Acta Materialia, 56, 5412-5425.

Han, H. N., Oh, C.-S., Kim, G. \& Kwon, O. 2009. Design method for TRIP-aided multiphase steel based on a microstructure-based modelling for transformation-induced plasticity and mechanically induced martensitic transformation. Materials Science and Engineering: A, 499, 462-468. 
Hane, K. F. \& Shield, T. W. 1998. Symmetry and microstructure in martensites. Philosophical Magazine A, 78, 1215-1252.

Hatem, T. \& Zikry, M. 2009. Dislocation density crystalline plasticity modeling of lath martensitic microstructures in steel alloys. Philosophical Magazine, 89, 3087-3109.

Iwamoto, T. 2004. Multiscale computational simulation of deformation behavior of TRIP steel with growth of martensitic particles in unit cell by asymptotic homogenization method. International Journal of Plasticity, 20, 841-869.

Jacques, P., Delannay, F. \& Ladrière, J. 2001a. On the influence of interactions between phases on the mechanical stability of retained austenite in transformation-induced plasticity multiphase steels. Metallurgical and Materials Transactions A, 32, 2759-2768.

Jacques, P., Furnémont, Q., Pardoen, T. \& Delannay, F. 2001b. On the role of martensitic transformation on damage and cracking resistance in TRIP-assisted multiphase steels. Acta Materialia, 49, 139152.

Jacques, P., Furnemont, Q., Lani, F., Pardoen, T. \& Delannay, F. 2007. Multiscale mechanics of TRIPassisted multiphase steels: I. Characterization and mechanical testing. Acta Materialia, 55, 36813693.

Jeong, W., Matlock, D. \& Krauss, G. 1993. Observation of deformation and transformation behavior of retained austenite in a $0.14 \mathrm{C}-1.2 \mathrm{Si}-1.5 \mathrm{Mn}$ steel with ferrite-bainite-austenite structure. Materials Science and Engineering: A, 165, 1-8.

Jia, N., Cong, Z., Sun, X., Cheng, S., Nie, Z., Ren, Y., Liaw, P. \& Wang, Y. 2009. An in situ high-energy $\mathrm{X}$-ray diffraction study of micromechanical behavior of multiple phases in advanced highstrength steels. Acta Materialia, 57, 3965-3977.

Kocks, U. 1976. Laws for work-hardening and low-temperature creep. Journal of Engineering Materials and Technology, 98, 76-85.

Kouznetsova, V. \& Geers, M. 2008. A multi-scale model of martensitic transformation plasticity. Mechanics of Materials, 40, 641-657.

Kuziak, R., Kawalla, R. \& Waengler, S. 2008. Advanced high strength steels for automotive industry. Archives of Civil and Mechanical Engineering, 8, 103-117.

Lani, F., Furnémont, Q., Van Rompaey, T., Delannay, F., Jacques, P. \& Pardoen, T. 2007. Multiscale mechanics of TRIP-assisted multiphase steels: II. Micromechanical modelling. Acta Materialia, 55, 3695-3705.

Leblond, J.-B., Mottet, G. \& Devaux, J. 1986a. A theoretical and numerical approach to the plastic behaviour of steels during phase transformations-I. Derivation of general relations. Journal of the Mechanics and Physics of Solids, 34, 395-409. 
Leblond, J., Mottet, G. \& Devaux, J. 1986b. A theoretical and numerical approach to the plastic behaviour of steels during phase transformations-II. Study of classical plasticity for ideal-plastic phases. Journal of the Mechanics and Physics of Solids, 34, 411-432.

Lee, M.-G., Kim, S.-J. \& Han, H. N. 2010a. Crystal plasticity finite element modeling of mechanically induced martensitic transformation (MIMT) in metastable austenite. International Journal of Plasticity, 26, 688-710.

Lee, M., Lim, H., Adams, B., Hirth, J. \& Wagoner, R. 2010b. A dislocation density-based single crystal constitutive equation. International Journal of Plasticity, 26, 925-938.

Levitas, V. I., Idesman, A. V., Olson, G. B. \& Stein, E. 2002. Numerical modelling of martensitic growth in an elastoplastic material. Philosophical Magazine A, 82, 429-462.

Lomholt, T. N., Adachi, Y., Bastos, A., Pantleon, K. \& Somers, M. A. 2013. Partial transformation of austenite in Al-Mn-Si TRIP steel upon tensile straining: an in situ EBSD study. Materials Science and Technology, 29, 1383-1388.

Manchiraju, S. \& Anderson, P. 2010. Coupling between martensitic phase transformations and plasticity: A microstructure-based finite element model. International Journal of Plasticity, 26, 1508-1526.

Morito, S., Huang, X., Furuhara, T., Maki, T. \& Hansen, N. 2006. The morphology and crystallography of lath martensite in alloy steels. Acta materialia, 54, 5323-5331.

Muránsky, O., Šittner, P., Zrník, J. \& Oliver, E. 2008. In situ neutron diffraction investigation of the collaborative deformation-transformation mechanism in TRIP-assisted steels at room and elevated temperatures. Acta Materialia, 56, 3367-3379.

Oliver, E., Withers, P., Daymond, M., Ueta, S. \& Mori, T. 2002. Neutron-diffraction study of stressinduced martensitic transformation in TRIP steel. Applied Physics A, 74, s1143-s1145.

Olson, G. \& Cohen, M. 1975. Kinetics of strain-induced martensitic nucleation. Metallurgical Transactions A, 6, 791-795.

Pan, H., Thamburaja, P. \& Chau, F. 2007. Multi-axial behavior of shape-memory alloys undergoing martensitic reorientation and detwinning. International Journal of Plasticity, 23, 711-732.

Peirce, D., Asaro, R. \& Needleman, A. 1982. An analysis of nonuniform and localized deformation in ductile single crystals. Acta metallurgica, 30, 1087-1119.

Perlade, A., Bouaziz, O. \& Furnemont, Q. 2003. A physically based model for TRIP-aided carbon steels behaviour. Materials Science and Engineering: A, 356, 145-152.

Ritchie, R. O., Knott, J. F. \& Rice, J. 1973. On the relationship between critical tensile stress and fracture toughness in mild steel. Journal of the Mechanics and Physics of Solids, 21, 395-410.

Sakuma, Y., Matlock, D. K. \& Krauss, G. 1992a. Intercritically annealed and isothermally transformed 0.15 Pct C steels containing 1.2 Pct Si-1.5 Pct Mn and 4 Pct Ni: Part II. effect of testing 
temperature on stress-strain behavior and deformation-induced austenite transformation. Metallurgical Transactions A, 23, 1233-1241.

Sakuma, Y., Matlock, D. K. \& Krauss, G. 1992b. Intercritically annealed and isothermally transformed 0.15 Pct C steels containing 1.2 Pct Si-1.5 Pct Mn and 4 Pct Ni: Part I. transformation, microstructure, and room-temperature mechanical properties. Metallurgical Transactions A, 23, 1221-1232.

Saylor, D. M., Fridy, J., El-Dasher, B. S., Jung, K.-Y. \& Rollett, A. D. 2004. Statistically representative three-dimensional microstructures based on orthogonal observation sections. Metallurgical and Materials Transactions A, 35, 1969-1979.

Sierra, R. \& Nemes, J. 2008. Investigation of the mechanical behaviour of multi-phase TRIP steels using finite element methods. International Journal of Mechanical Sciences, 50, 649-665.

Soulami, A., Choi, K. S., Liu, W. N., Sun, X., Khaleel, M. A., Ren, Y. \& Wang, Y.-D. 2010. Predicting Fracture Toughness of TRIP 800 Using Phase Properties Characterized by In-Situ High-Energy X-Ray Diffraction. Metallurgical and Materials Transactions A, 41, 1261-1268.

Stewart, J., Jiang, L., Williams, J. \& Chawla, N. 2012. Prediction of bulk tensile behavior of dual phase stainless steels using constituent behavior from micropillar compression experiments. Materials Science and Engineering: A, 534, 220-227.

Stringfellow, R., Parks, D. \& Olson, G. 1992. A constitutive model for transformation plasticity accompanying strain-induced martensitic transformations in metastable austenitic steels. Acta Metallurgica et Materialia, 40, 1703-1716.

Suiker, A. S. \& Turteltaub, S. 2005. Computational modelling of plasticity induced by martensitic phase transformations. International Journal for Numerical Methods in Engineering, 63, 1655-1693.

Sun, X., Choi, K. S., Liu, W. N. \& Khaleel, M. A. 2009. Predicting failure modes and ductility of dual phase steels using plastic strain localization. International Journal of Plasticity, 25, 1888-1909.

Thamburaja, P. 2005. Constitutive equations for martensitic reorientation and detwinning in shapememory alloys. Journal of the Mechanics and Physics of Solids, 53, 825-856.

Tjahjanto, D., Turteltaub, S., Suiker, A. \& Van der Zwaag, S. 2006. Modelling of the effects of grain orientation on transformation-induced plasticity in multiphase carbon steels. Modelling and Simulation in Materials Science and Engineering, 14, 617.

Turteltaub, S. \& Suiker, A. 2005. Transformation-induced plasticity in ferrous alloys. Journal of the Mechanics and Physics of Solids, 53, 1747-1788.

Turteltaub, S. \& Suiker, A. 2006. A multiscale thermomechanical model for cubic to tetragonal martensitic phase transformations. International journal of solids and structures, 43, 4509-4545. 
Wang, L. \& Speer, J. G. 2013. Quenching and Partitioning Steel Heat Treatment. Metallography, Microstructure, and Analysis, 2, 268-281.

Wang, X., Xu, B. \& Yue, Z. 2008. Micromechanical modelling of the effect of plastic deformation on the mechanical behaviour in pseudoelastic shape memory alloys. International Journal of Plasticity, 24, 1307-1332.

Weinberger, C. R., Battaile, C. C., Buchheit, T. E. \& Holm, E. A. 2012. Incorporating atomistic data of lattice friction into BCC crystal plasticity models. International Journal of Plasticity, 37, 16-30.

Woo, W., Em, V., Kim, E.-Y., Han, S., Han, Y. \& Choi, S.-H. 2012. Stress-strain relationship between ferrite and martensite in a dual-phase steel studied by in situ neutron diffraction and crystal plasticity theories. Acta Materialia, 60, 6972-6981.

Wu, Q., Shanthraj, P. \& Zikry, M. 2013. Modeling the heterogeneous effects of retained austenite on the behavior of martensitic high strength steels. International journal of fracture, 184, 241-252.

\section{Figure Captions:}

Figure 1. Microstructure of the as-received Q\&P980 sheet steel. (a) Secondary electron image showing the necklace microstructure of martensite surrounding ferrite grains. (b) High magnification image showing the three phases: ferrite $(\mathrm{F})$, martensite $(\mathrm{M})$ and retained austenite $(\mathrm{RA})$. The RA precipitates are located at interfaces and triple junctions and identified by black arrows in (b). (c) EBSD map and the associated inverse pole figures for both FCC and BCC phases in the as-received steel. Black regions in (c) are retained austenite grains.

Figure 2. Uniaxial tensile stress-strain curves for the as-received Q\&P980 sheet steel with loading axis aligned parallel and normal to the rolling direction (RD).

Figure 3. Histograms of size distributions of retained austenite particles in Q\&P980 steel, (a) in asreceived condition, (b) after 5\% global tensile strain, (c) after $12 \%$ global tensile strain, and (d) after tensile fracture.

Figure 4. Compression stress-strain curves for ferrite micropillars (Pillars 1-5); inverse pole figure showing the axial orientation (along loading axis) of ferrite micropillars (Pillars 1-5); and SEM images of two deformed ferrite micropillars (Pillars 1 and 4). 
Figure 5. Compression stress-strain curves for martensite micropillars (Pillars 1-4); and SEM images of two deformed martensite micropillars (Pillars 3 and 4).

Figure 6. Schematic showing the initial three phase (ferrite, martensite and retained austenite) microstructure; zoomed in view of a retained austenite grain in the reference undeformed configuration; and zoomed in view of a retained austenite grain after deformation showing the deformed microstructure containing untransformed austenite and martensite variants formed due to martensitic transformation along $(i)^{\text {th }}$ transformation system.

Figure 7. A three-phase representative volume element of Q\&P980 steel. The different colors of element groups in ferrite and retained austenite phase mark different grains whereas the different colors of element groups in martensite phase mark martensite blocks.

Figure 8. Comparison of experimental and calculated compression stress-strain curves of (a) three micropillars of ferrite phase and (b) two micropillars of martensite phase.

Figure 9. Comparison of calculated (open symbols) and experimental (closed symbols) (a) uniaxial tensile stress-strain curves, and (b) work-hardening response under uniaxial tension. In the calculations two volume fractions of retained austenite, $f_{R A}=0.1$ and 0.08 , and for each case, three volume fractions of martensite, $f_{M}=0.42,0.44$, and 0.46 are considered. In (b), $\sigma$ is the logarithmic stress and $\varepsilon$ is the logarithmic strain. The inset in (b) shows an enlarged view of the range, $0.11 \leq \varepsilon \leq 0.12$. The detailed legend of the plot in (b) is same as (a).

Figure 10. Comparison of the evolution of average volume fraction of the new martensite (formed due to deformation-induced martensitic transformation) estimated from the RVE calculations and that measured in experiments from the interrupted tensile tests.

Figure 11. (a) The distribution of new martensite volume fraction, $\xi_{M}$, formed due to martensitic transformation in retained austenite grains at a macroscopic nominal strain of $15 \%$. The ferrite and martensite elements are hidden. (b) Histograms of martensite volume fraction, $\xi_{M}$, in retained austenite grains at three macroscopic nominal strain levels. (c) Histograms of size of retained austenite grains at the 
initial undeformed state and at two macroscopic nominal strain levels. All the results are for a RVE calculations with $f_{M}=0.44$ and $f_{R A}=0.1$.

Figure 12. Partitioning of (a) plastic equivalent strain and (b) plastic equivalent strain rate among the three phases with macroscopic nominal strain. The results are shown for a RVE with $f_{M}=0.44$ and $f_{R A}=0.1$.

Figure 13. (a) Evolution of the axial stress component $\sigma_{11}$ in the individual phases with macroscopic nominal strain. (b) Evolution of the von Mises effective stress $\sigma_{\text {mises }}$ in the individual phases with volume averaged von Mises effective strain $\varepsilon_{\text {mises }}$. The results are shown for a RVE with $f_{M}=0.44$ and $f_{R A}=0.1$.

Figure 14. Comparison of calculated and experimental (closed symbols) uniaxial tensile stress-strain curves for volume fraction of retained austenite, $f_{R A}=0$ and three volume fractions of martensite, $f_{M}=0.45,0.5$, and 0.55 . The corresponding values of the volume fraction of ferrite, $f_{F}$, are also given in the legend.

Figure 15. (a) Stress-strain curves and (b) volume fraction of product martensite in a model microstructure with $f_{M}=0.44$ and $f_{R A}=0.1$ in which various deformation mechanisms occurs in the retained austenite. In curves labeled TRANS, only the austenite-martensite transformation contributes to the plastic strain, and austenite and product martensite are elastic. In curves labeled TRANS+MART, both the transformation and slip in the martensite contribute to plastic strain. In the remaining curve, the transformation, slip in austenite and slip in martensite are permitted.

Figure 16. The descending cumulative distribution function (CDF) of (a) maximum principal stress, (b) plastic equivalent strain and (c) stress triaxiality in the individual phases in a RVE with $f_{M}=0.44$ and $f_{R A}=0.1$ at macroscopic nominal strain of $15 \%$. The vertical axis is on logarithmic scale.

Figure 17. The descending cumulative distribution function (CDF) of (a) maximum principal stress, (b) plastic equivalent strain and (c) stress triaxiality at interphase boundaries in a RVE with $f_{M}=0.44$ and 
$f_{R A}=0.1$ at macroscopic nominal strain of $15 \%$. In the legend $F-M-R A$ is ferrite-martensite-retained austenite triple junction, $F-M$ is ferrite-martensite dual-phase boundary, $F-R A$ is ferrite-retained austenite dual-phase boundary and $M-R A$ is martensite-retained austenite dual-phase boundary. 
Figure 1.
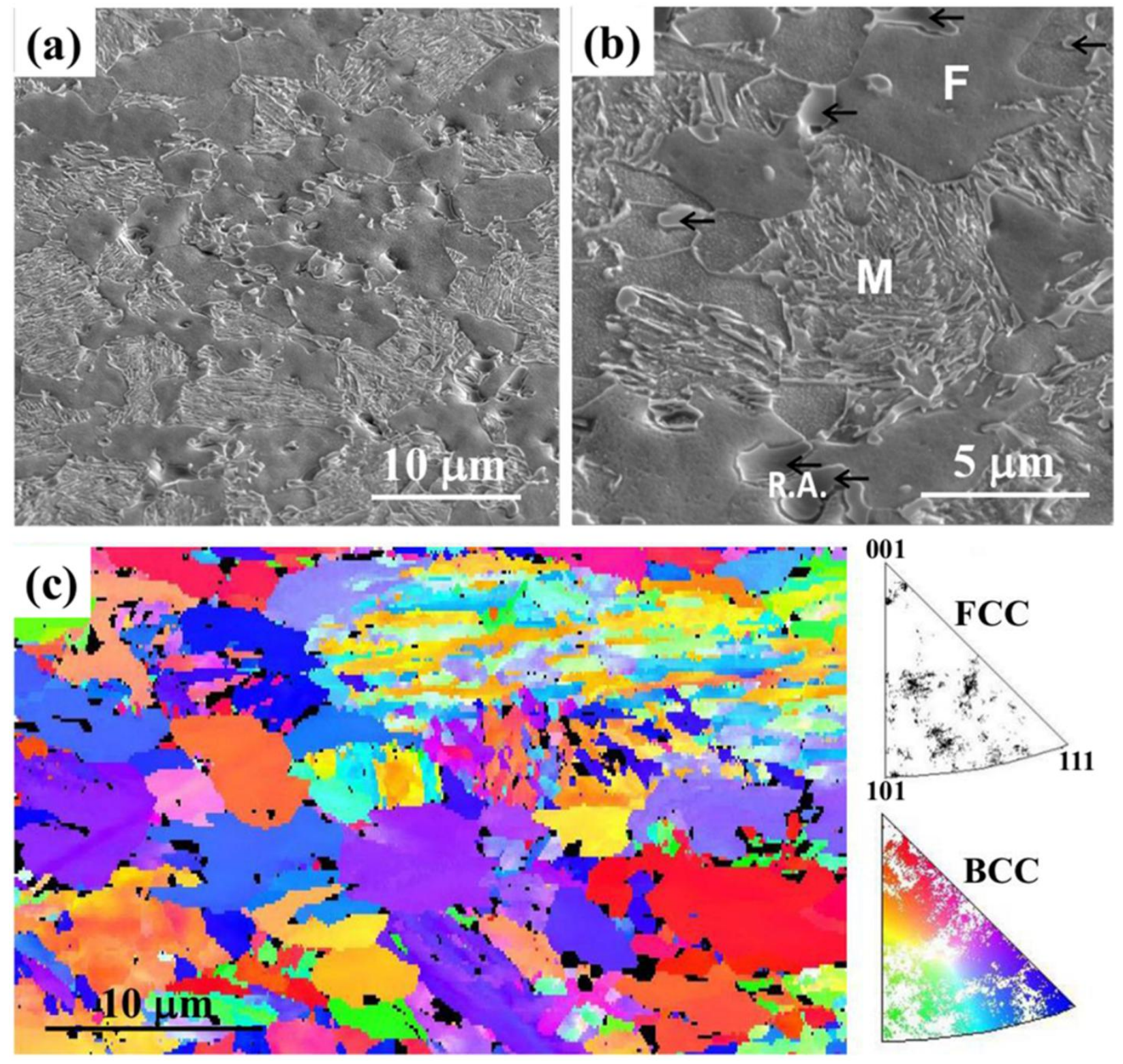
Figure 2.

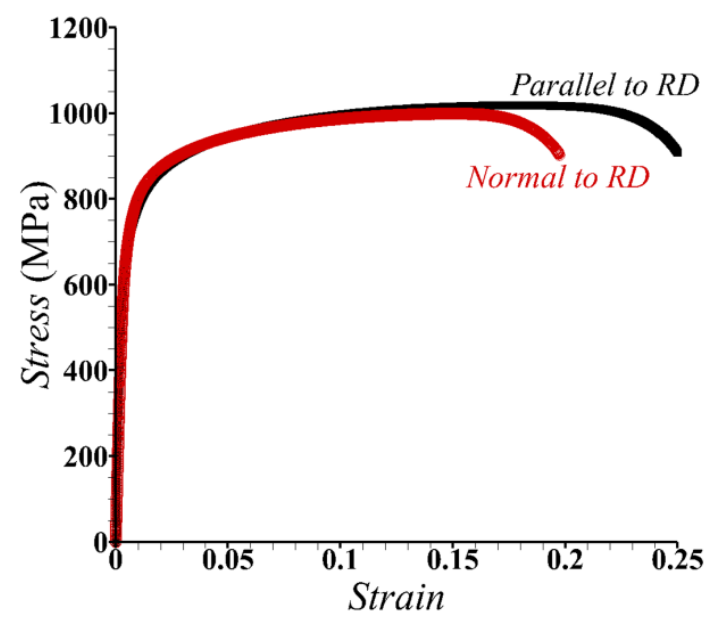


Figure 3.

(a)

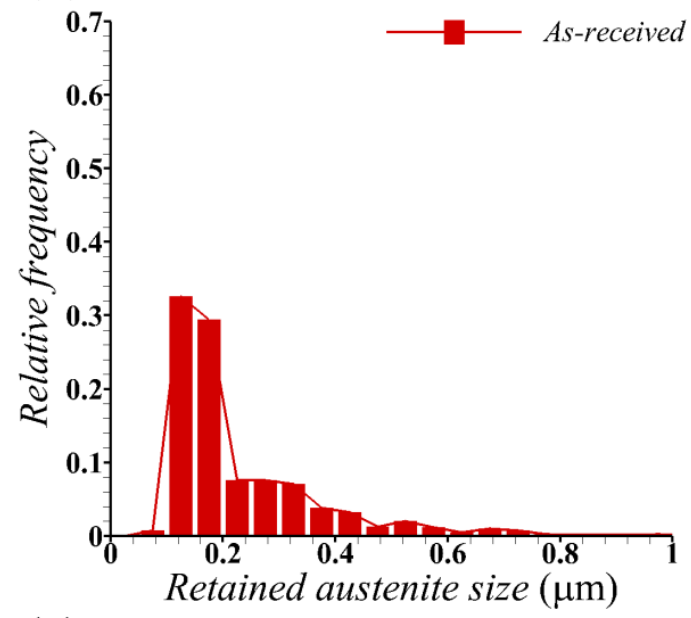

(c)

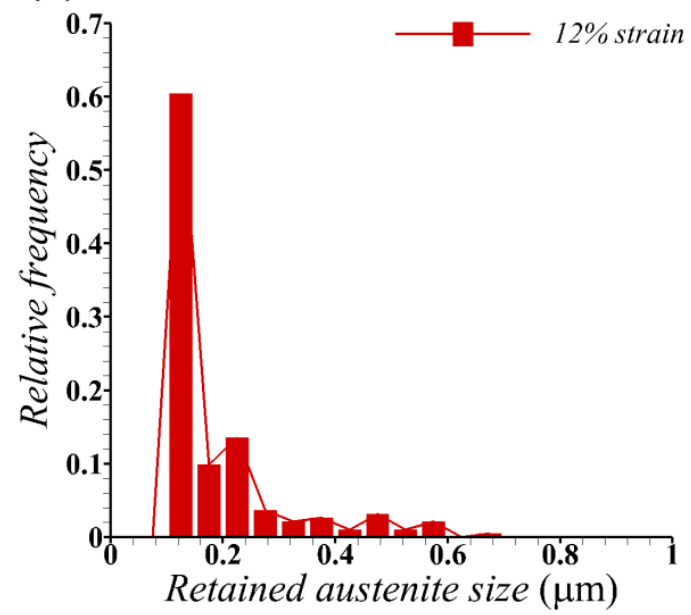

(b)

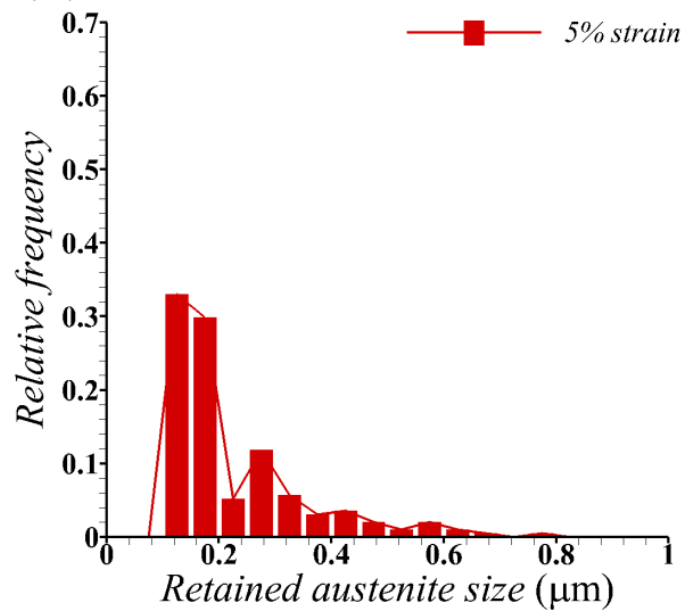

(d)

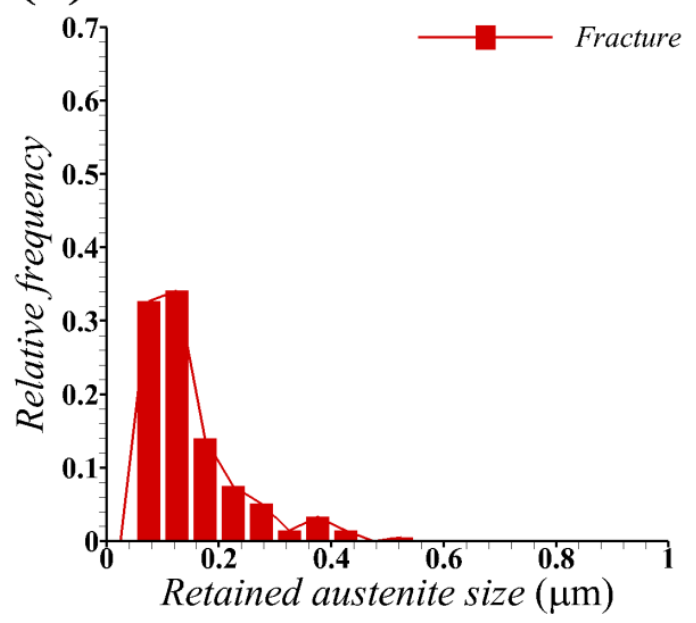


Figure 4.
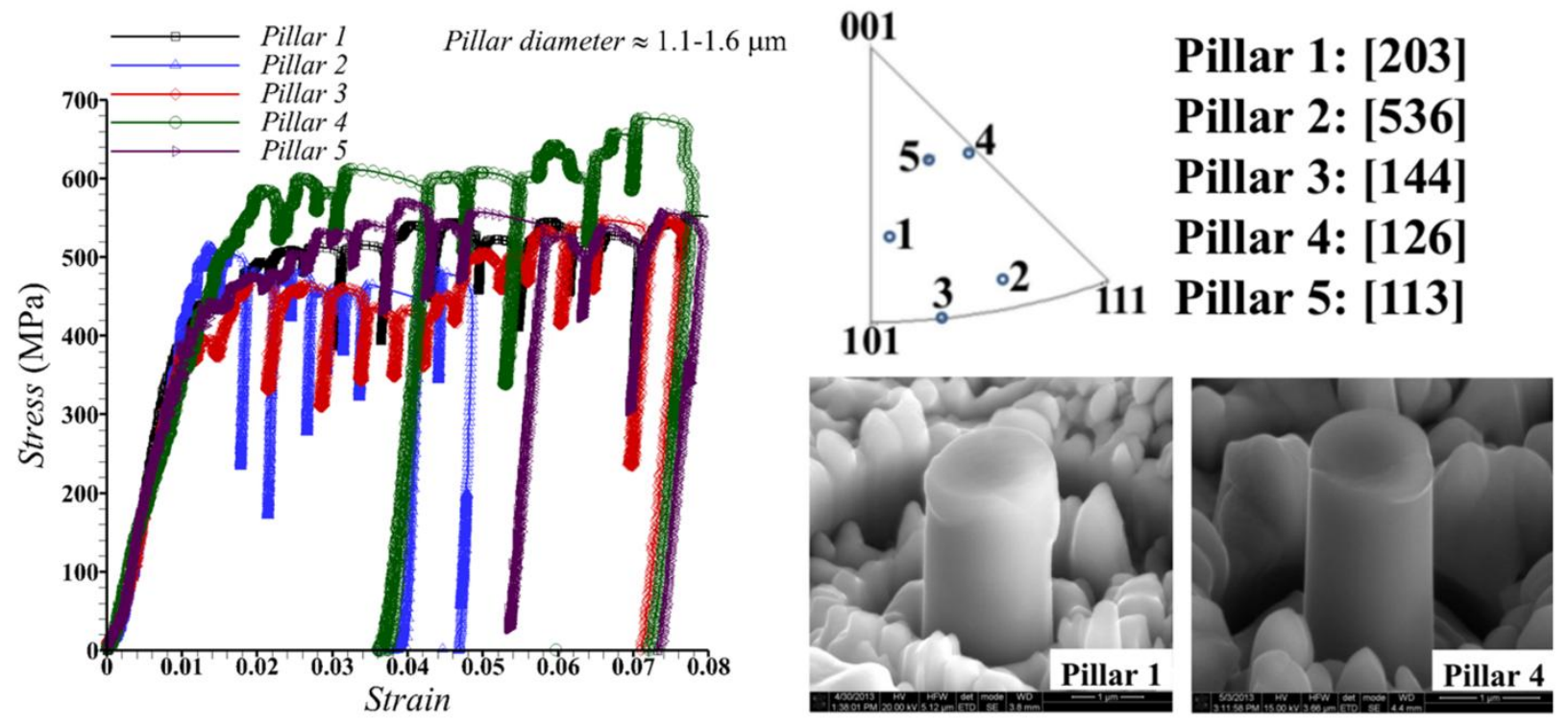
Figure 5.
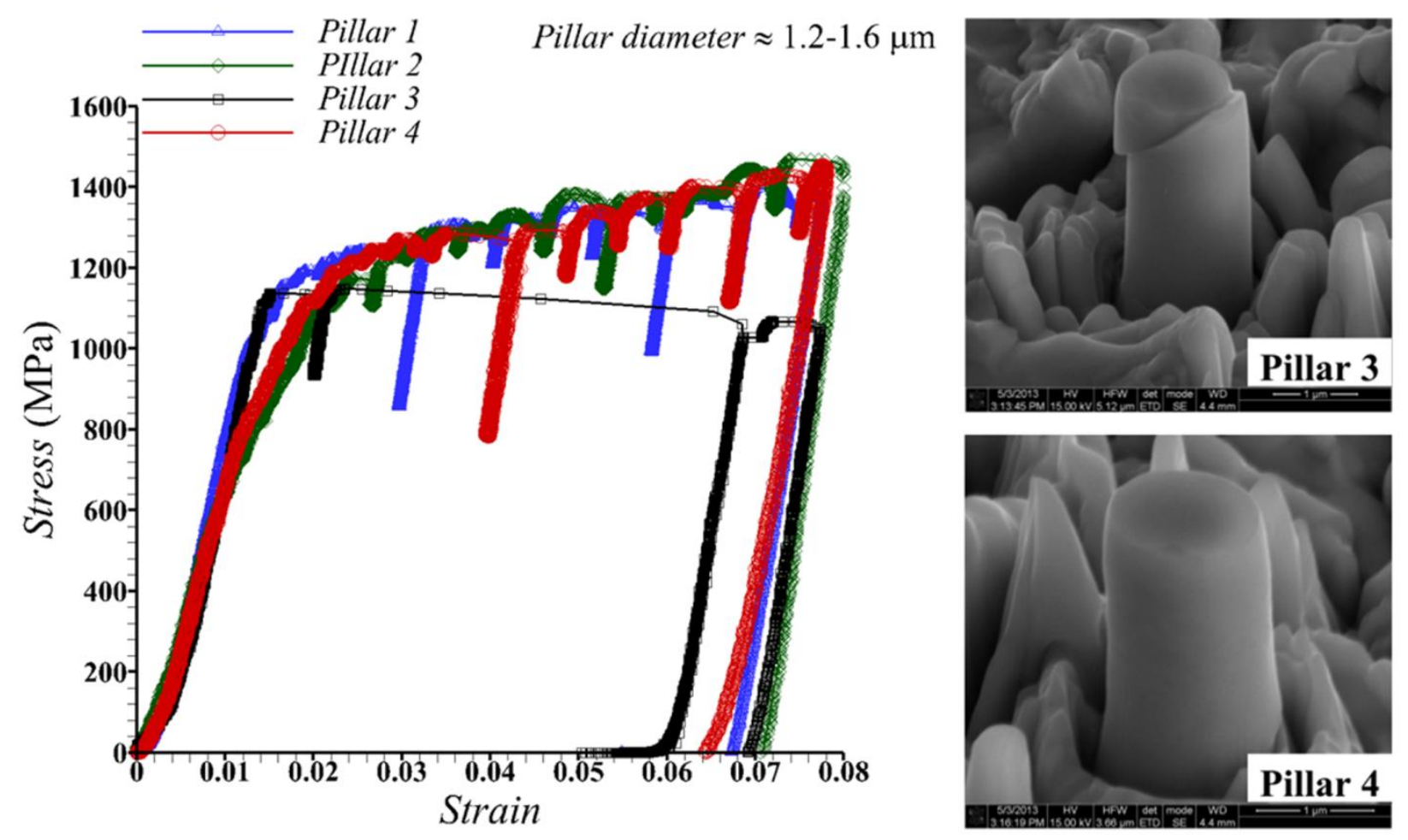
Figure 6.

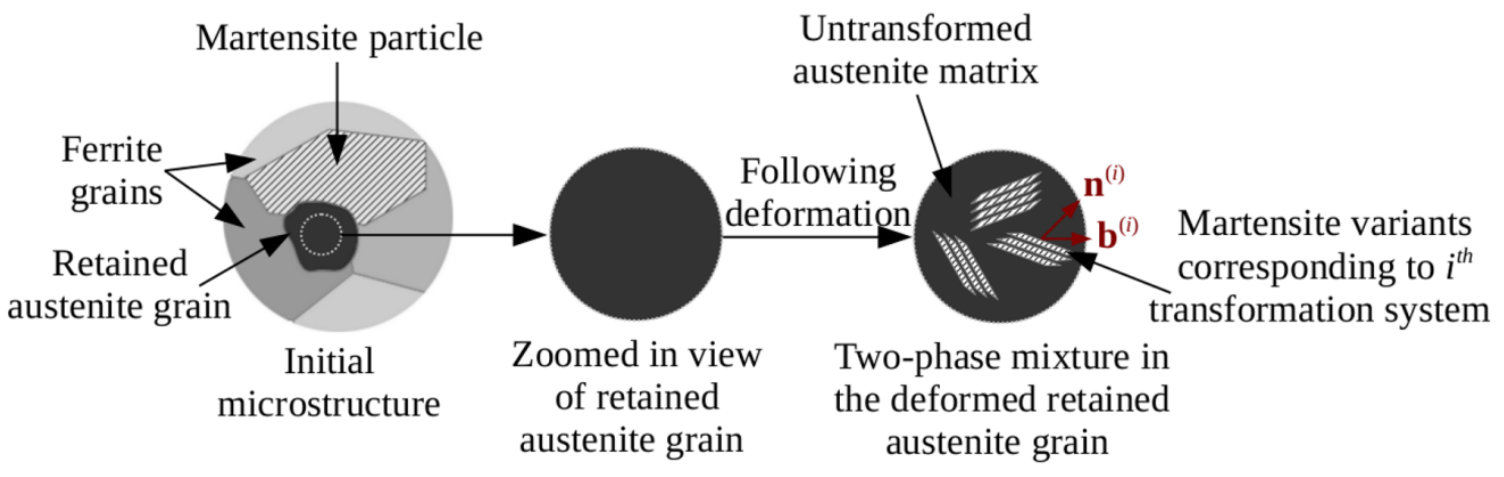


Figure 7.

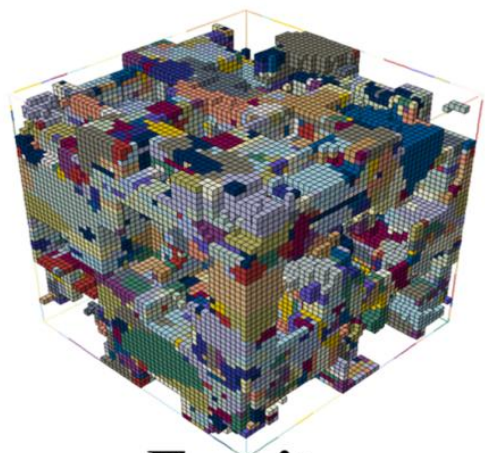

Ferrite

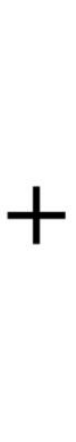

1

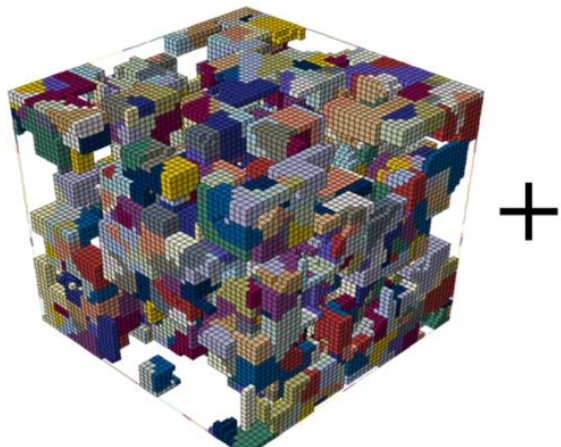

Martensite

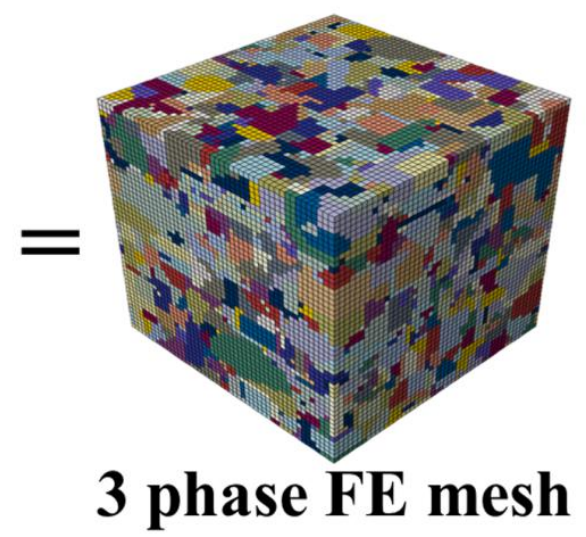

3 phase FE mesh

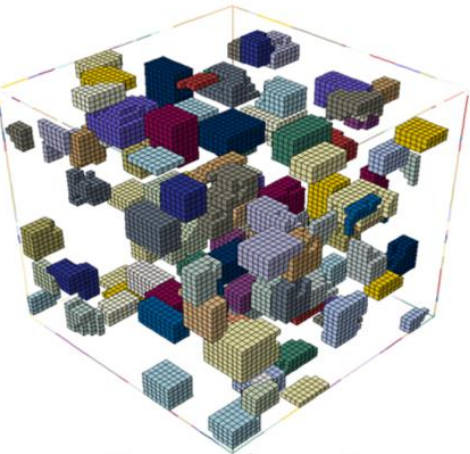

Retained Austenite

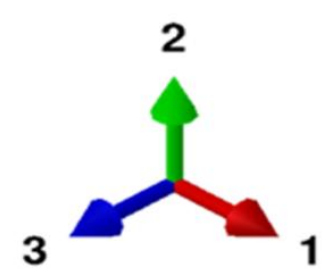


Figure 8.

(a)

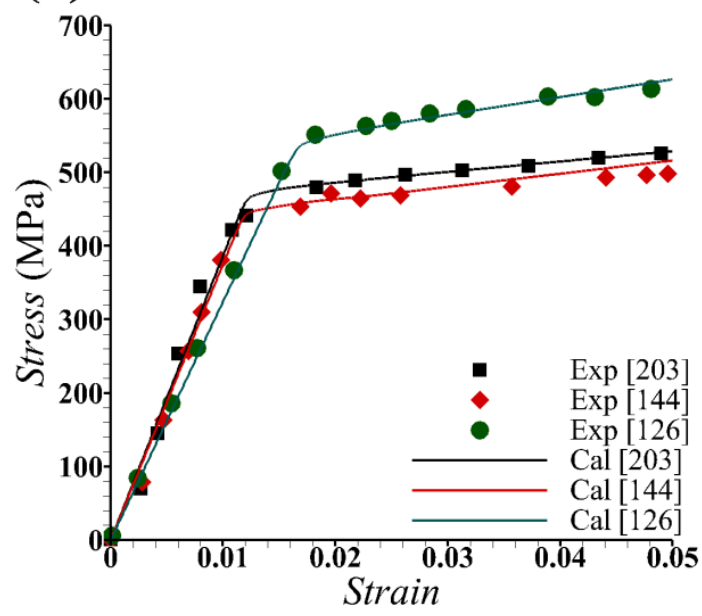

(b)

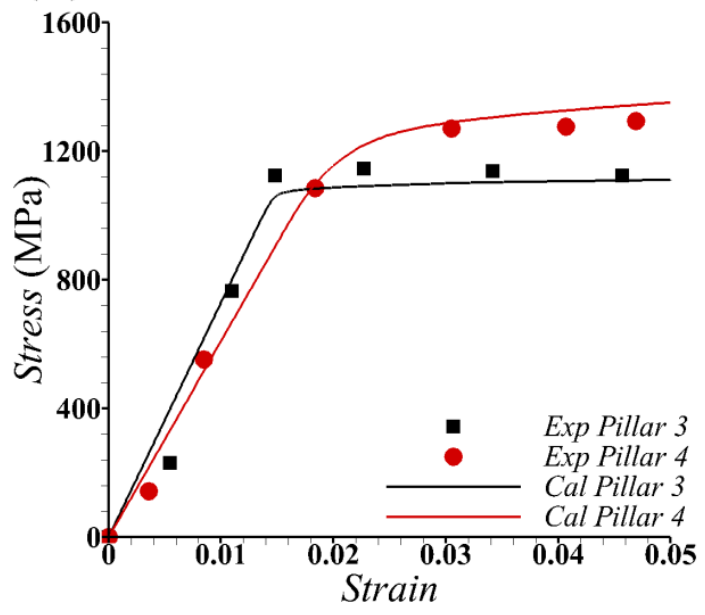


Figure 9.

(a)

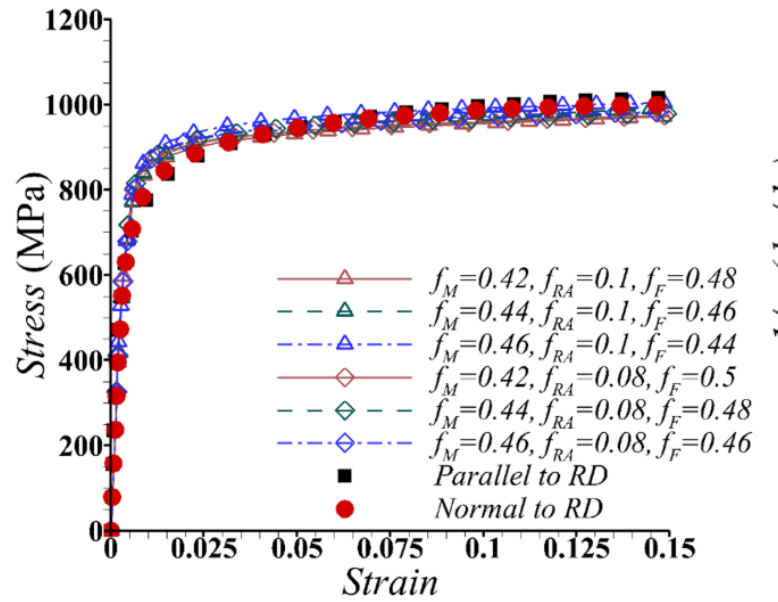

(b)

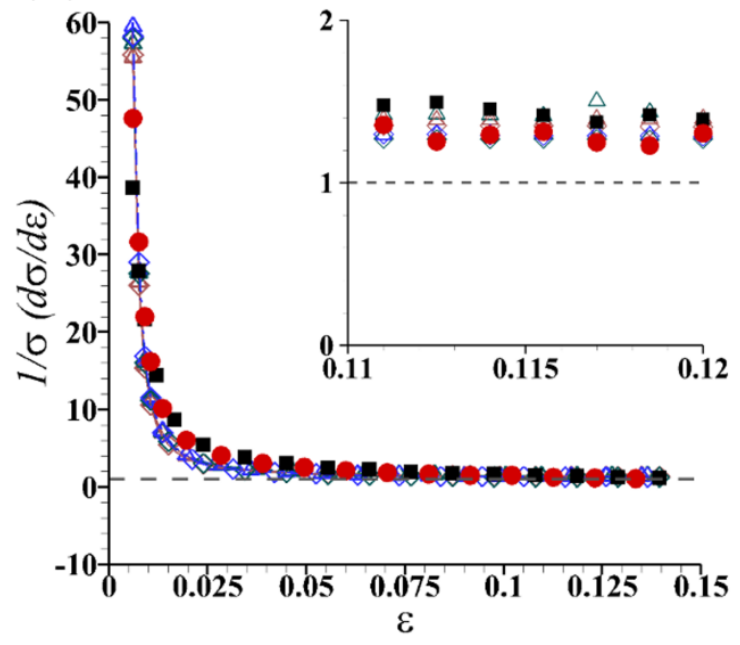


Figure 10.

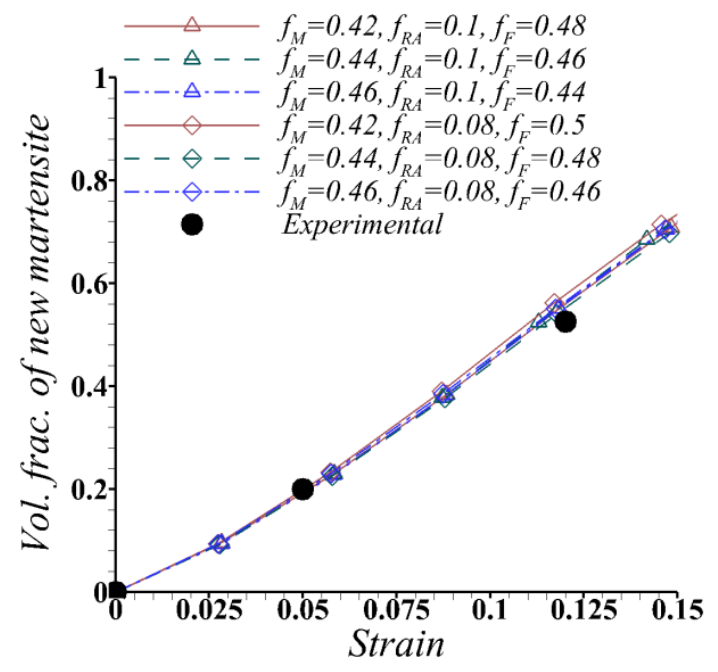


Figure 11.

(b)

(a)
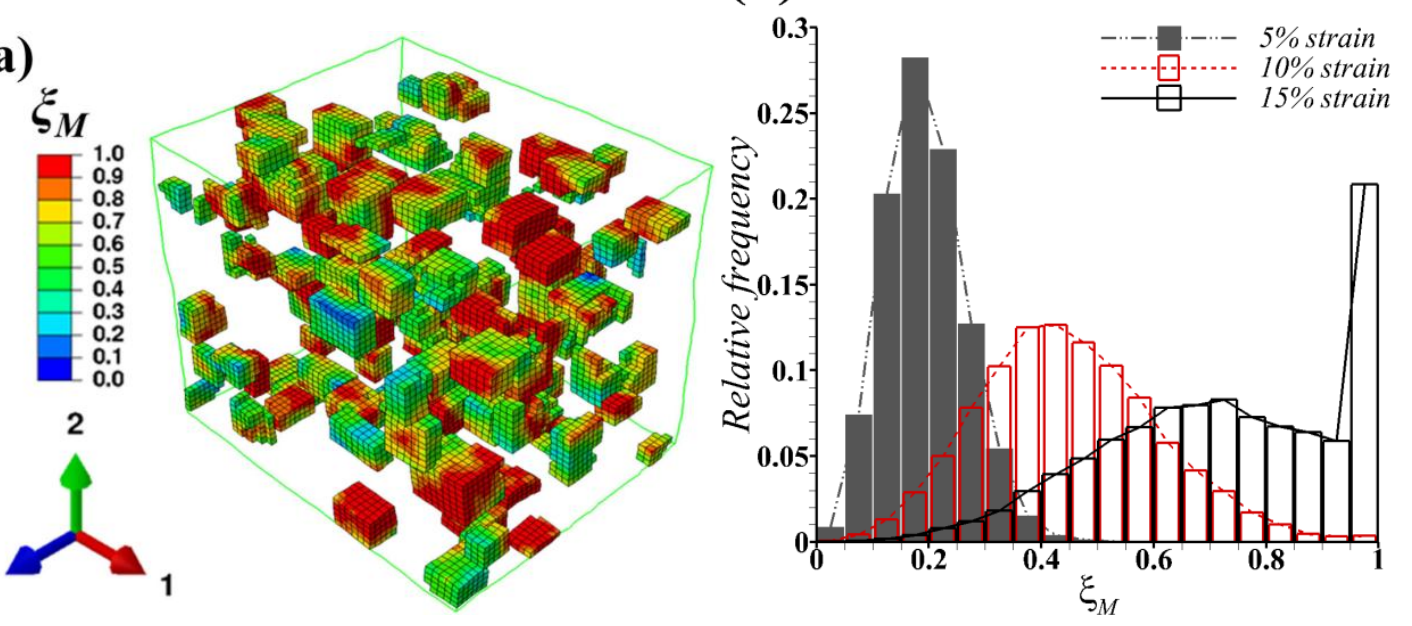

(c)

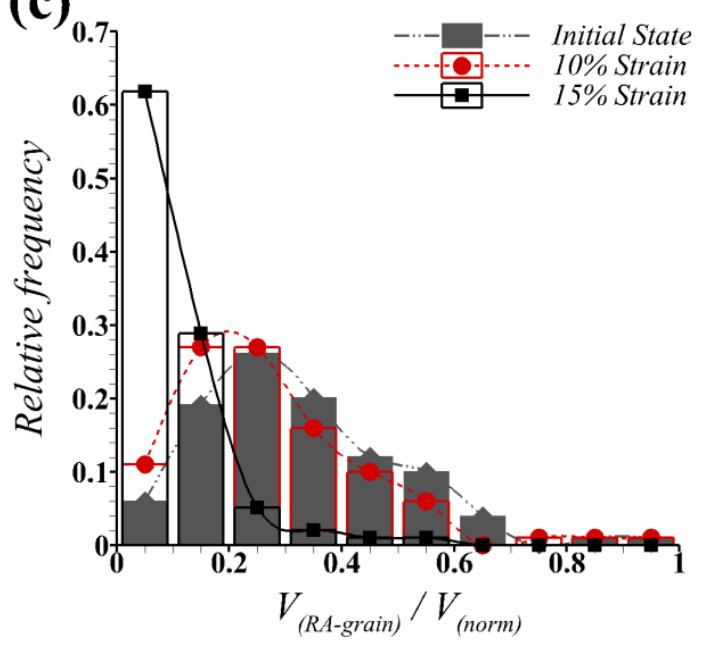


Figure 12.

(a)

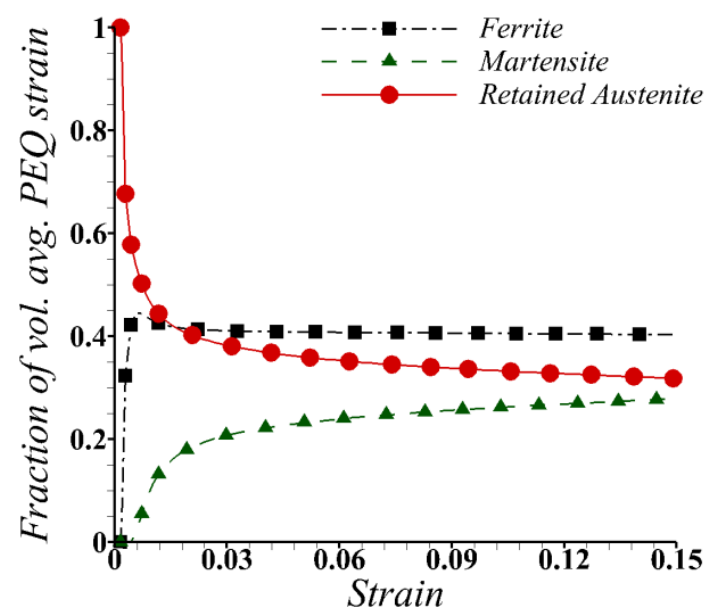

(b)

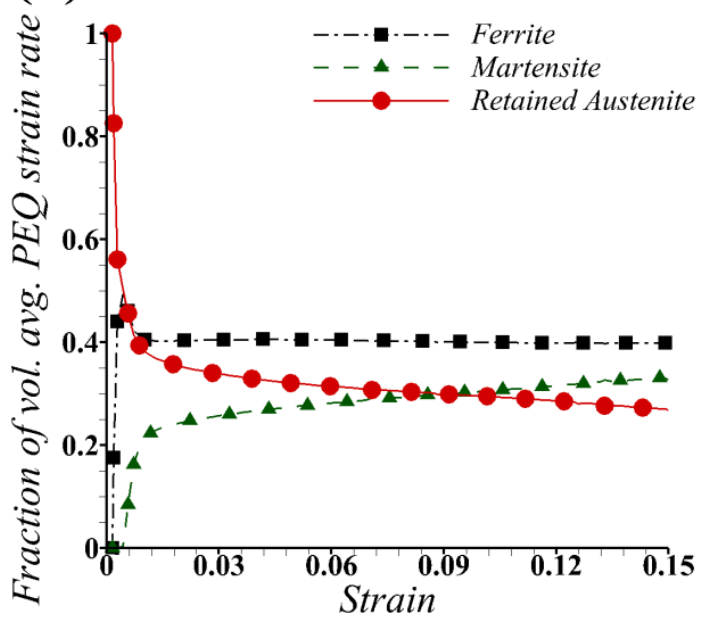


Figure 13.

(a)

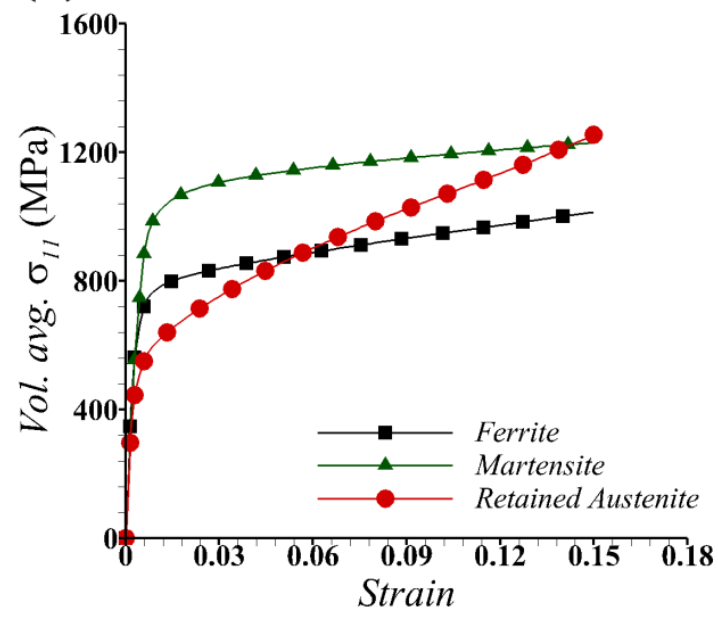

(b)

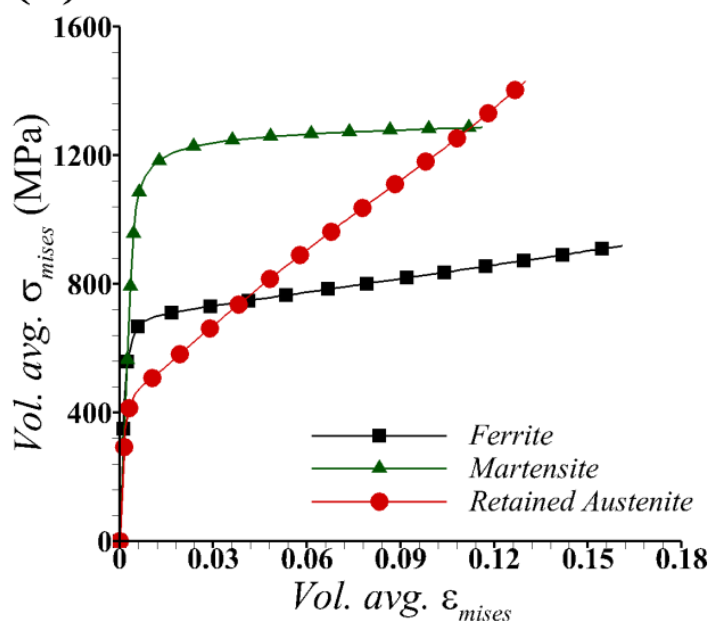


Figure 14.

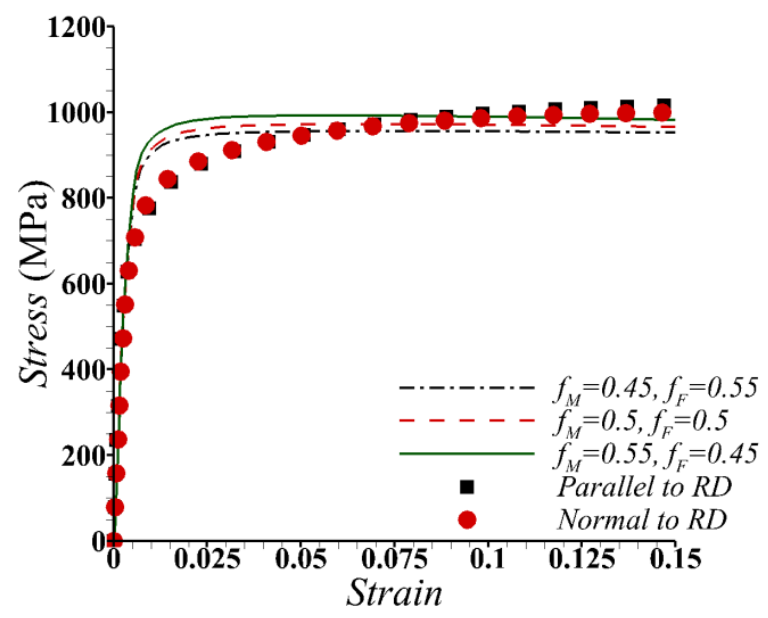


Figure 15.

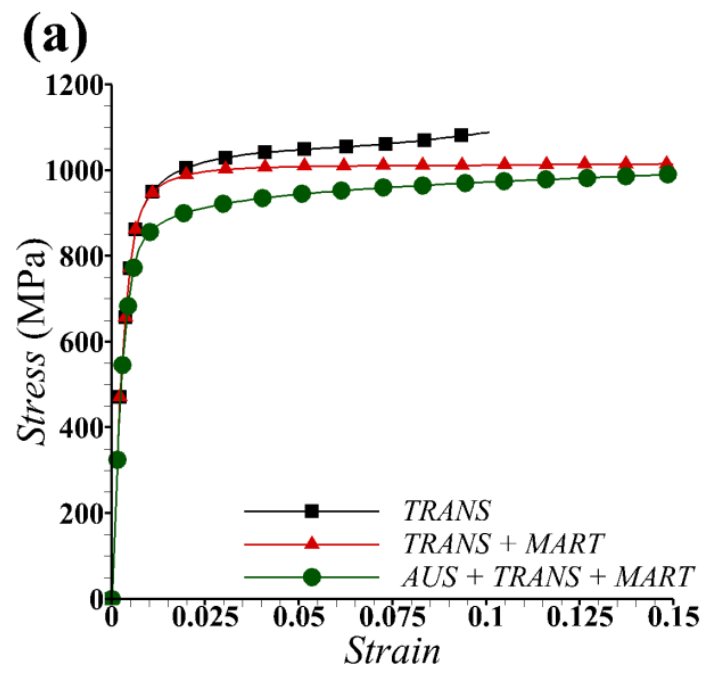

(b) $\square$ TRANS

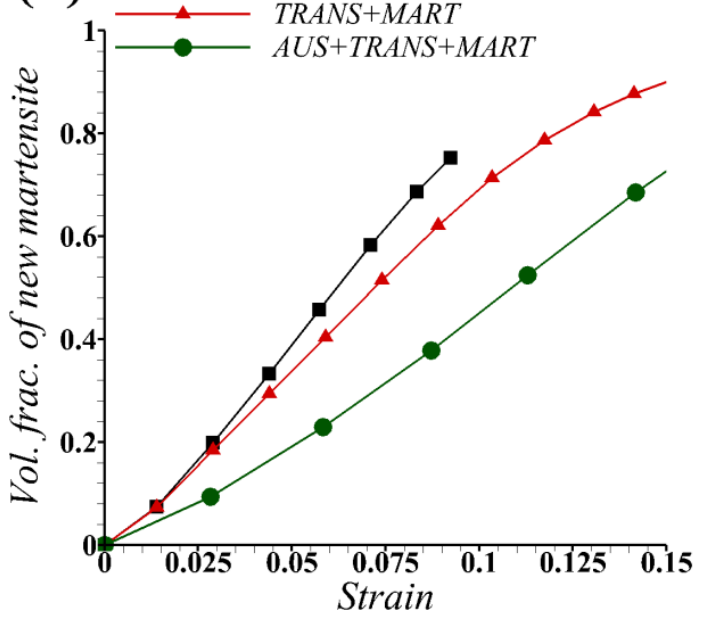


Figure 16.
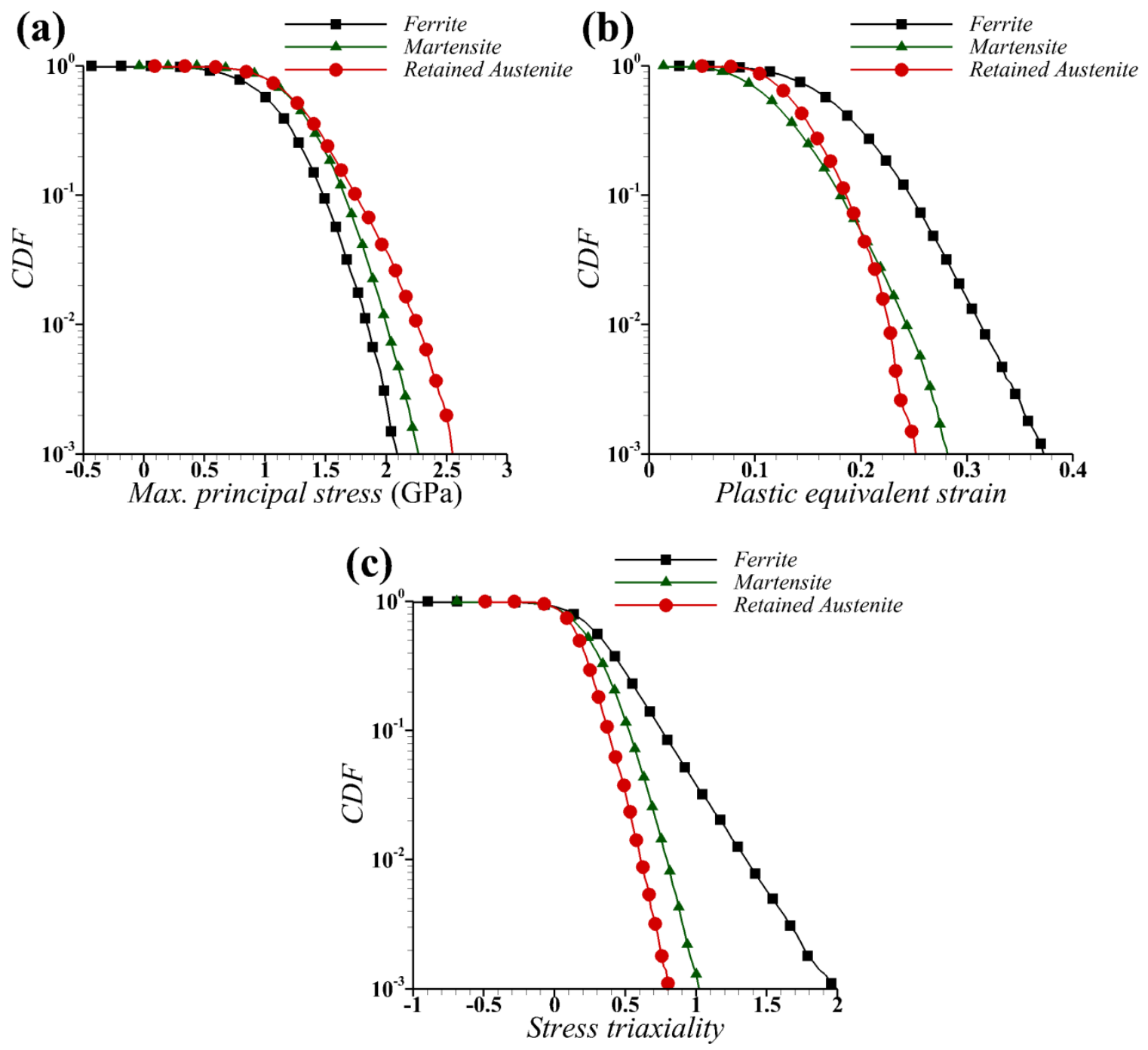
Figure 17.
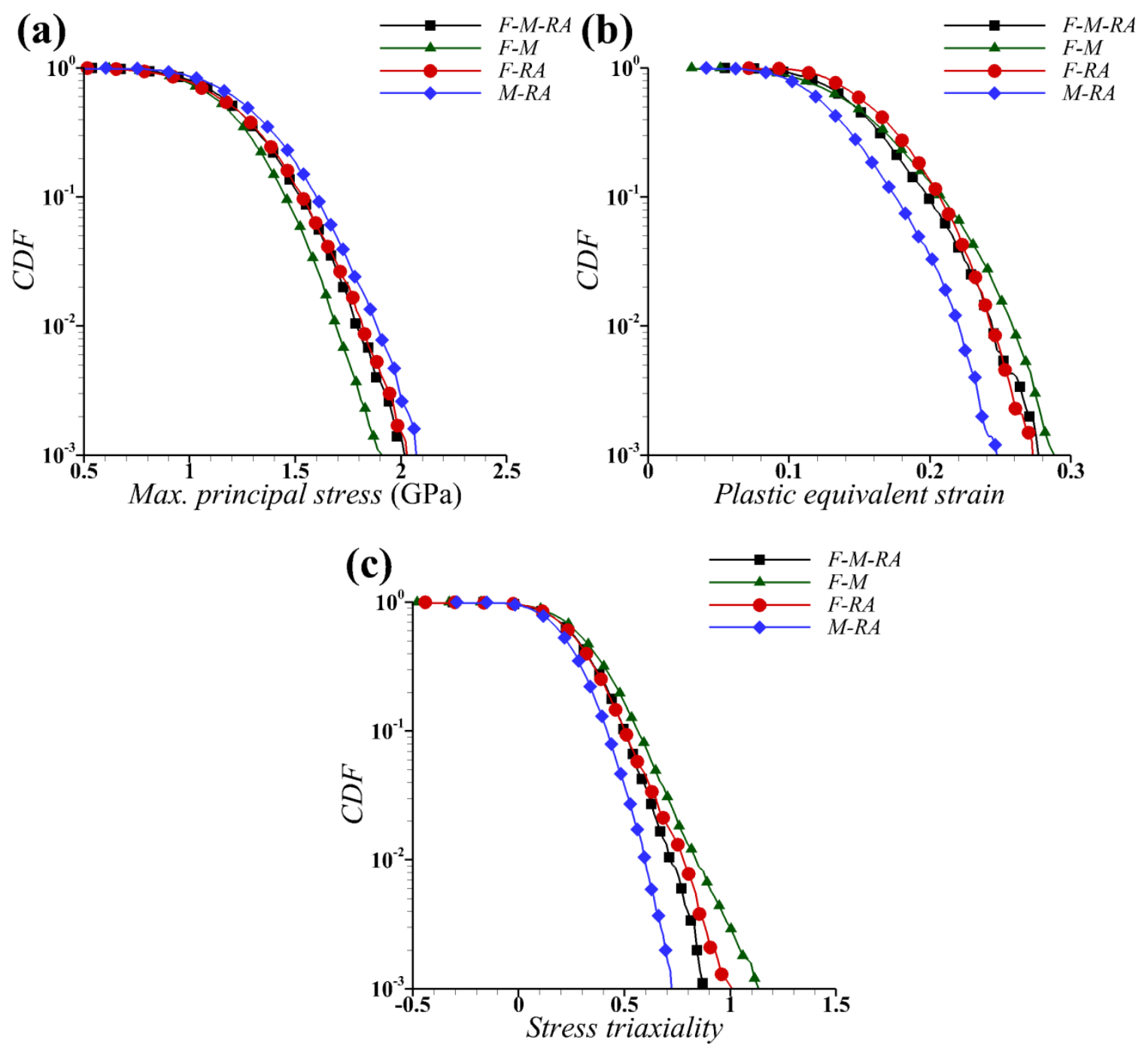
Table 1. The values of the material parameters for the constitutive models of ferrite, martensite and retained austenite phase in Q\&P980 steel.

\begin{tabular}{|c|c|}
\hline Material parameters & Values \\
\hline \multicolumn{2}{|l|}{ For ferrite phase } \\
\hline Reference strain rate, $\dot{\gamma}_{0}$ & $4.77 \times 10^{-7} \mathrm{~s}^{-1}$ \\
\hline Stress exponent, $m$ & 54.27 \\
\hline Initial hardening rate, $h_{0}$ & $110.4 \mathrm{MPa}$ \\
\hline Saturation hardening rate, $h_{s}$ & 109.2MPa \\
\hline Initial flow stress, $\mathrm{g}_{0}$ & $255.32 \mathrm{MPa}$ \\
\hline Saturation flow stress, $\mathrm{g}_{s}$ & $4.2 \mathrm{GPa}$ \\
\hline Characteristic shear strain, $\gamma_{0}$ & 91 \\
\hline Latent hardening coefficient, $f_{0}$ & 46.43 \\
\hline Latent hardening coefficient, $q$ & 1.4 \\
\hline Non-Schmid effect parameter, $a_{1}$ & 0.61 \\
\hline Non-Schmid effect parameter, $a_{2}$ & 0.01 \\
\hline Non-Schmid effect parameter, $a_{3}$ & 0.21 \\
\hline \multicolumn{2}{|l|}{ For martensite phase } \\
\hline Reference strain rate, $\dot{\gamma}_{0}$ & $1.68 \times 10^{-3} \mathrm{~s}^{-1}$ \\
\hline Stress exponent, $m$ & 71.2 \\
\hline Dislocation nucleation rate, $k_{a}$ & 94.6 \\
\hline Dislocation annihilation rate, $k_{b}$ & 0.23 \\
\hline Initial dislocation density, $\rho_{0}$ & $3.98 \times 10^{13} \mathrm{~m}^{-2}$ \\
\hline \multicolumn{2}{|l|}{ For retained austenite phase } \\
\hline \multicolumn{2}{|l|}{ 1. Martensitic Transformation } \\
\hline Reference transformation rate, $\dot{\xi}_{0}$ & $0.01 \mathrm{~s}^{-1}$ \\
\hline
\end{tabular}




\begin{tabular}{|c|c|}
\hline Reference transformation strength, $\tau_{0}$ & $25.0 \mathrm{MPa}$ \\
\hline \multicolumn{2}{|l|}{ 2. Austenite Plasticity } \\
\hline Reference strain rate, $\dot{a}_{0}$ & $0.0001 \mathrm{~s}^{-1}$ \\
\hline Stress exponent, $k$ & 10.0 \\
\hline Initial hardening modulus, $h_{0}$ & $600.0 \mathrm{MPa}$ \\
\hline Initial value of current strength, $\mathrm{g}_{0}$ & $450.0 \mathrm{MPa}$ \\
\hline Saturation value of current strength, $\mathrm{g}_{s}$ & $75.0 \mathrm{MPa}$ \\
\hline Latent hardening coefficient, $q$ & 1.0 \\
\hline \multicolumn{2}{|l|}{ 3. New martensite Plasticity } \\
\hline Reference strain rate, $\dot{\gamma}_{0}$ & $1.68 \times 10^{-3} \mathrm{~s}^{-1}$ \\
\hline Stress exponent, $m$ & 71.2 \\
\hline Dislocation nucleation rate, $k_{a}$ & 80.0 \\
\hline Dislocation annihilation rate, $k_{b}$ & 0.15 \\
\hline Initial dislocation density, $\rho_{0}$ & $6.5 \times 10^{13} \mathrm{~m}^{-2}$ \\
\hline
\end{tabular}

